\title{
Interpersonal factors and mental well-being are associated with accuracy in judging the veracity of political news
}

\section{Paul Rauwolf}

School of Human and Behavioural Sciences, Bangor University, Bangor, UK

\section{Correspondence}

Paul Rauwolf, School of Human and Behavioural Sciences, Bangor University, Brigantia Building, Bangor LL57 2AS, UK. Email: p.rauwolf@bangor.ac.uk

\begin{abstract}
More work needs to be done to understand how mental well-being and interpersonal factors are associated with biases in judging the veracity of true and false political information. Three days before the 2020 U.S. presidential election, 477 participants guessed the veracity of true and false political statements. Interpersonal factors (e.g., high prosociality and a need to belong) and mental health risk factors (e.g., high depressive symptoms and low eudaimonic well-being) were highly associated with believing false information. Further, positive well-being was associated with assessing news with a partisan bias. Next, hierarchical regression was used to better understand the combination of factors which best predict accurate judgments. To reduce the chances of overfitting, out-of-sample validation was used. About $40 \%$ of the variance for believing false information was explained by high prosociality and low well-being. In addition, well-being mediated the effects of political ideology when assessing the veracity of political information.
\end{abstract}

\section{KEYWORDS}

eudaimonic well-being, interpersonal, mental health, misinformation, truth bias

\section{1 | INTRODUCTION}

The ability to differentiate true from false information is a vital skill in the 21st century (Lazer et al., 2018; Van Bavel et al., 2021). This is particularly true during election cycles, where the amount of false information which crosses social media accounts increases (Allcott \& Gentzkow, 2017). To better understand those who are most vulnerable to false information, recent work has begun to diagnose the individual risk factors associated with inaccurately assessing the veracity of political information (Ecker et al., 2022; Pennycook \& Rand, 2021; Scheufele \& Krause, 2019; Sindermann et al., 2020). While invaluable work has shown that difficulty differentiating true from false political information is linked to cognitive processes, political partisanship, and socio-demographics (Martel et al., 2020), less is known about whether difficulty judging the veracity of political information is associated with individual differences in mental well-being and interpersonal factors. The goal of this work was two-fold. First, it explored whether various interpersonal and well-being factors were associated with difficulty judging the veracity of both true and false political news statements, presented in the lead-up to the 2020 U.S. presidential election. Second, this study sought to understand the best combination of well-being and interpersonal factors which predicted difficulty in assessing the accuracy of political statements.

The meaning behind the study of "misinformation," "disinformation," and "fake news" has a complex past. Some define misinformation and disinformation in mutually exclusive terms, where disinformation represents false information that is shared with the intention to deceive, where misinformation represents false information that is shared in good faith (Tandoc et al., 2018). Others define misinformation as "any information that turns out to be false" (Ecker et al., 2022), thus disinformation is a subset of misinformation. Further, the term "fake news" seems to change definitions depending on the context (Egelhofer \& Lecheler, 2019). This 
work focused on analyzing individual accuracy when confronted with true and false political statements. The intentions behind the political statements were not considered. So, in this work, misinformation is defined as any information that turns out to be false (Ecker et al., 2022; Guess \& Lyons, 2020; Lazer et al., 2018), and the terms "disinformation" and "fake news" are not used.

Recent work has found that difficulty distinguishing between true and false political information is linked to cognitive processes, political partisanship, and socio-demographics. Reduced analytical thinking is associated with difficulty differentiating between true and false political information (Bronstein et al., 2019; Pennycook \& Rand, 2019, 2021; Sindermann et al., 2020), but increasing one's time to reflect on political information has been shown to increase one's ability to accurately assess political information (Bago et al., 2020). Age is associated with an increased likelihood to come in contact with and share false information (Brashier \& Schacter, 2020; Grinberg et al., 2019). There is evidence that individuals tend to believe news that is concordant with their political views (Anthony \& Moulding, 2019; Bago et al., 2020; Vegetti \& Mancosu, 2020), and those with conservative beliefs are particularly prone to consumption of misinformation (Grinberg et al., 2019) and inaccurate beliefs (Garrett \& Bond, 2022; Pennycook \& Rand, 2019, 2021).

\section{1 | Impact of mental well-being}

One under-represented area of research is (broadly speaking) mental well-being. The effects of mental well-being, such as depression or negative affect, on distinguishing true from false political information are only starting to receive interest. Preliminary evidence suggests that powerful affective states (Martel et al., 2020) or experimentally manipulating anger and anxiety (Weeks, 2015) can bias truth assessment of political statements. Further, schizotypal personality traits are associated with vulnerability to believing false information (Anthony \& Moulding, 2019). Outside of the political realm, belief in misinformation about Covid-19 has been linked to depression (De Coninck et al., 2021).

It is surprising that the effects of mental health on assessing political information are only starting to garner interest, given the large repository of work finding comorbidities between mental health risk factors and various attentional and information processing biases. Information avoidance is associated with low self-esteem (Howell \& Shepperd, 2016; Wiersema et al., 2012) and experiences of selfaffirmation can reduce information avoidance (Howell \& Shepperd, 2012, 2017). Depression is associated with attentional deficits (Gotlib \& Joormann, 2010; Keller et al., 2019). Negative affect is linked to reduced working memory (Curci et al., 2013). Further, individuals more easily recall memories that share the valence of their current mood (Holland \& Kensinger, 2010). Interestingly, positive emotions have also been linked to information processing biases, as happiness has been linked to gullibility when trying to detect deception in those who might have committed a theft (Forgas \& East, 2008). It is possible that these biases in information processing, memory, and attention may affect the evaluation of political information.

The present study explores whether the ability to distinguish between true and false political information is associated with various aspects of well-being. However, evaluating well-being is non-trivial as it is a complex, heterogeneous construct, which can be divided into several subcategories (Keyes, 2006; Martela \& Sheldon, 2019). One common framework is to subdivide well-being into hedonic well-being (sometimes called subjective well-being) and eudaimonic well-being (Ryan \& Deci, 2001). Hedonic well-being measures personal experiences of positive and unpleasant feelings, and can be further subdivided in trait and state measures, which evaluate hedonic experiences over various time frames (Tov, 2018). Eudaimonic wellbeing considers our ability to pursue our potential and is often measured by querying feelings of autonomy and purpose in life (Ryff, 2017; Ryff \& Singer, 2008).

Since attentional and information processing biases have been linked to different aspects of well-being such as depression (Gotlib \& Joormann, 2010; Keller et al., 2019), negative affect (Curci et al., 2013), low self-esteem (Howell \& Shepperd, 2016; Wiersema et al., 2012), and momentary mood (Forgas \& East, 2008; Holland \& Kensinger, 2010), it is vital to understand which sub-categories of well-being are most strongly linked to difficulty judging the veracity of political statements. As such, this work took an exploratory approach to evaluating the associations between well-being and the ability to accurately judge the veracity of both true and false political statements. The study considered the effects of depression, self-esteem, eudaimonic well-being, and various measures of affect along different time scales. While this study was exploratory and considered several measures of well-being, the analysis attempted to reduce the risk of false positives (i.e., type I errors) with methods such as out-of-sample cross validation and conservative adjustments for multiple comparisons (details discussed below).

\section{2 | Impact of interpersonal behaviors and social factors}

It has also been argued that the impact of interpersonal factors on judging the veracity of political statements requires increased attention (Weeks \& Gil de Zúñiga, 2021). Humans are complex social creatures and socially motivated goals might override (or at least affect) the need for accurate beliefs (Caplan, 2001; Rauwolf et al., 2015; Van Bavel \& Pereira, 2018; Wilson et al., 2021). In its most broad definition, interpersonal factors are factors which affect how an individual behaves in the social environment (Byrd \& McKinney, 2012). This can include factors pertaining to (a) how the individual reacts to a social environment (sometimes called interpersonal behaviors), but also (b) how the social environment itself impacts the individual (sometimes called social factors) (Cameron \& Granger, 2018). This work considered whether individual differences in under-considered interpersonal behaviors and social factors were associated with difficulty judging the veracity of political statements. Specifically, this 
work focused on interpersonal factors that had been found to be related to information processing biases in other, related areas.

From the perspective of interpersonal behaviors, a large body of work has considered how social identity motivations might bias beliefs (Van Bavel et al., 2021). It has been argued that individuals might bias their beliefs about the world to help maintain a positive image of their social/political group (Sternisko et al., 2020). In line with this theory, there is robust evidence that individuals are more likely to believe (Bago et al., 2020; Pereira et al., 2021; Vegetti \& Mancosu, 2020) and share (Osmundsen et al., 2021; Rathje et al., 2021) information that supports their political party.

While the work on social/political identity has made excellent progress, less work has considered whether individual differences in socially motivated interpersonal behaviors predict biased perceptions in the veracity of political statements. If social motives are playing a large part in how individuals navigate the political landscape, then prioritizing social interactions or a willingness to conform to the group may be associated with biasing one's belief in information about that group. Preliminary research has offered mixed results. Calvillo et al. (2021) found that agreeableness and conscientiousness, but not extraversion (as measured by the Big Five Inventory) were associated with the ability to differentiate true from false information. Sindermann et al. (2021), however, found no effect of agreeableness or conscientiousness, but did find that extraversion and authoritarian submission were linked to difficulty differentiating true and false headlines, while interpersonal trust was linked to improved differentiation.

While the present work specifically focused on individual differences in judging the veracity of political statements in the lead up to the 2020 U.S. presidential election, there is evidence that individual differences in social identity motives are associated with biased beliefs in very related areas. Individual differences in strength of partisan beliefs are associated with a willingness to share fake news on social media (Osmundsen et al., 2021). Further, there is a large body of work which has considered the individual differences associated with believing conspiracy theories (Douglas et al., 2017). Conspiracy theories are a specific type of misinformation, which argue that secret plots between people are causing events in the world (Douglas et al., 2019). Belief in conspiracy theories has been associated with various social motives, such as belief in a group's greatness and need for external validation (Douglas, 2021; Douglas et al., 2017). Although, Fasce et al. (2021) found somewhat mixed support that need to belong and intergroup anxiety were associated with conspiracy, paranormal, and pseudo-scientific beliefs.

The present study sought to extend our knowledge of the influence of social identity motives by evaluating whether biased truth assessment was associated with individual differences in (a) one's need to belong, and (b) preferential behavior toward ingroup members. Given social/political identity motives, it has been hypothesized that a high need to belong might lead individuals to bias their assessment of information to fall in line with the group (Fasce et al., 2021). However, to the author's knowledge, beyond conspiracy theories, no one has explicitly tested whether need to belong is associated with accuracy in judging a variety of political statements. Similarly, the tendency to give preferential treatment to ingroup members might be associated with a willingness to believe political congruent information. This study tested that hypothesis. Preferential treatment of ingroup members was measured by the treatment of ingroup and outgroup members in a Dictator game (details explained below) (Engel, 2011). To the author's knowledge, no one has measured whether preferential behavior toward ingroup members (i.e., a willingness to pay a cost to give them money) is associated with biased truth assessment of political information.

Outside of social identity theory, generosity has been linked to a general trusting nature (Bekkers, 2007; Chaudhuri \& Gangadharan, 2007). As such, it was hypothesized that generosity might be associated with a tendency to believe most political statements (and thus be vulnerable to misinformation). To test this hypothesis, participant's generosity was evaluated using the Dictator game (Engel, 2011).

An individual's social environment (i.e., social factors) is also associated with biases in judging the veracity of political statements. Homogeneity of social networks (i.e., homophily) is associated with biased truth assessment of political information. Individuals bias their social media interactions with those who share their partisan beliefs (Del Vicario et al., 2016; Mosleh et al., 2021) and ideologically biased news consumption is associated with increased misperceptions (Garrett et al., 2016). To compare the effect-size of homophily to other interpersonal and well-being factors, this study sought to reproduce this effect by asking participants the percentage of their friendships which share their political candidate. It was hypothesized that increased homophily would be associated with an increased bias to believe information supporting one's candidate.

It is well-known that, in a variety of circumstance, individuals will go to great lengths to avoid social ostracization, including conforming to those who threaten to ostracize (Williams \& Nida, 2011). Recently, there is evidence to suggest that ostracism from one's political party is associated with increased willingness to believe false information that supports that party (Garrett et al., 2020). However, individuals likely have friendships across party lines. To the author's knowledge, no one has considered how threats of ostracism from friends supporting the other candidate might affect the assessment of true and false political statements. The present work asked how much the results of the 2020 U.S. presidential election would affect friendships that (a) supported the individual's candidate, and (b) supported the other main candidate. It was hypothesized that individuals would be more willing to believe positive statements about a friend's candidate, if the individual felt that the friendship would be impacted by the results of the election.

\section{\begin{tabular}{l|l} 
1.3 & The strongest combination of factors
\end{tabular}}

Beyond considering the effects of various well-being and interpersonal factors in isolation, this study took an exploratory approach to understand the combination of psychological factors which best 
predict accuracy. The aforementioned, extant literature has considered whether specific aspects of well-being and interpersonal factors affect truth assessment. However, to the author's knowledge, no one has considered (a) which parts of well-being and interpersonal factors are most important in predicting biases in truth assessment, and (b) how the effects of interpersonal and well-being factors relate. Since many of the aforementioned factors covary, it is vital to understand which factors predict accuracy above and beyond other factors. Doing so can help us better understand the most important archetypes of factors associated with vulnerability to biased beliefs. If interpersonal factors, hedonic well-being, and eudaimonic well-being continued to explain variance in truth assessments, even when controlling for each other, then this would provide evidence that all three aspects are important. If, however, interpersonal measures and eudaimonic well-being did not predict accuracy after controlling for hedonic well-being, then this would provide evidence that eudaimonic well-being and interpersonal factors are not useful in predicting biases in truth assessment beyond their relationship with hedonic wellbeing.

With the intent to uncover the strongest predictors of covarying well-being and interpersonal measures, two other measurements were added to the study: (a) political ideology, and (b) age. There is a large body of work demonstrating that conservative beliefs are associated with a tendency to believe more false information (Garrett \& Bond, 2022; Pennycook \& Rand, 2019, 2021). However, conservatism is also associated with well-being. Conservatives tend to score higher in self-reported measures of happiness (Wojcik et al., 2015) and also emotionally react more strongly when faced with negative events (Joel et al., 2014). Since well-being and conservatism covary, a measure of conservatism was added to assess whether either measure continued to predict truth assessment after controlling for the other Similarly, age has been associated with coming in contact with and sharing false information (Brashier \& Schacter, 2020; Grinberg et al., 2019), but age is also correlated with various aspects of mental well-being (Ryff et al., 2021). As such, age was included in the analysis to assess whether well-being and age continued to predict truth assessment after controlling for each other.

Importantly, while it is valuable to consider how various factors combine to predict vulnerability to biases in judging the veracity of political information, analyzing models with multiple variables can be prone to overfitting, reducing the likelihood of replicability (Yarkoni \& Westfall, 2017). To navigate these concerns, the "best subset selection" algorithm was used to understand how the shared (and unshared) variance between various factors combined to best predict accuracy rates. Best subset selection finds the best multiple regression model while reducing the risks of overfitting by using crossvalidation (Gómez \& Prokopyev, 2021; Hastie et al., 2001; James et al., 2013). Several combinations of factors were evaluated on their ability to predict out-of-sample data (via 10-fold cross validation). Interpersonal, well-being, and political factors were considered in tandem. The goal was to understand which combination of factors best predicted accuracy in assessing true and false political statements whilst reducing the likelihood of overfitting (details described below).

\subsection{Summary}

The goal of this work was two-fold. First, it sought to explore whether various under-considered interpersonal and well-being factors were associated with biases in judging the accuracy of political news statements. To do this, I analyzed whether each interpersonal and wellbeing factor was correlated with accuracy in judging the veracity of true and false political statements which were found on fact-checking websites in the lead up to the 2020 U.S. presidential election. While I have argued why the various well-being and interpersonal measures may be associated with biased truth assessments, this work was still exploratory. As such, since several variables were considered, and since this could inflate the risk of false positives, the present work took a conservative approach to analysis. All correlations were Bonferroni corrected.

The second aim of this study was to better understand the combination of factors which best predict accuracy. Since many of the factors covary, the aim was to find out which factors continued to explain more variance, even when controlling for other factors. To do this, and to reduce the risk of overfitting, out-of-sample validation (i.e., cross validation) was used.

\section{2 | METHOD}

Three days prior to the 2020 U.S. presidential election, 500 participants from the United States completed an online survey using Amazon Mechanical Turk (MTurk). They were asked to judge the veracity of true and false political statements. They also completed questionnaires assessing various aspects of their (a) mental well-being, (b) interpersonal factors, and (c) partisan/political beliefs. The goal was to assess whether mental well-being, interpersonal factors, and political ideology were associated with accuracy when judging the veracity of political statements.

Ethics for this study was approved by Bangor University (Study ID: 2020-16814). An a priori power analysis showed that a sample size of 462 had $90 \%$ power to detect small-medium correlation effects ( $r=.15)$. As such, a sample size of 500 was used.

\section{1 | Transparency and openness}

All data and research materials are available at https://osf.io/3rxv5/? view_only=cfd69f3e9e1a48deb699c2658c27f8af.

\section{2 | Participants}

Participants were only allowed to participate if their MTurk approval rating was above $95 \%$, since such individuals have been shown to have better attention rates than university students (Hauser \& Schwarz, 2016). Participants were paid $\$ 2$ to complete a 15 -min questionnaire. Since many of the measures depended on comparing 
congruent and incongruent party affiliations, 20 participants were excluded because they did not have a preference on who won the election. A further three participants were excluded because they failed an attention check ("To monitor quality, please reply 'Neither agree nor disagree' to this question" [Brawley \& Pury, 2016]). Prior to starting, participants acknowledged that they understood that they could withdraw at any time.

The final dataset included 477 participants (mean age: $38.78, S D$ : 11.33). The distribution of gender identity was non-binary (2), female (188), male (282), other non-specified (1), and preferred not to say (4). 232 of the participants supported Biden, and 245 supported Trump.

\section{3 | Materials}

\subsection{1 | Judging the veracity of political statements}

Historically, when participants are asked to judge the veracity of political statements, protocols have varied slightly. In most studies, participants are shown a series of true and false political statements, the veracity of which have been externally verified (e.g., through factchecking sites). Participants are asked to judge whether each statement is true or false. However, protocols vary on how participants are asked to make these judgments. Some protocols only ask whether each statement is true or false with a binary option (Bago et al., 2020; Sindermann et al., 2021). Others use Likert scales where participants denote how true they believe the statement to be (e.g. 1-not at all accurate, 2-not very accurate, 3-somewhat accurate, and 4-very accurate) (Bronstein et al., 2019; Martel et al., 2020; Pennycook \& Rand, 2019). Other protocols ask participants to guess the veracity of the statement while simultaneously noting the certainty of their decision (e.g. 1-definitely false, 2probably false, 3-probably true, and 4-definitely true) (Tappin et al., 2020; Weeks, 2015). In this study, participants were told that the statements had been externally verified as true or false; as such it seemed less necessary to ask participants to denote a gradation of accuracy. So, participants were asked to denote their subjective certainty in the judgments as per Tappin et al. (2020). However, since the main hypotheses of this work focused on accuracy of judging the veracity of statements, the certainty dimension was not analyzed.

In this study, participants were asked to rate the veracity of 28 political statements found on fact-checking websites. They were told that the statements had been labeled true or false by factchecking sites. As per Tappin et al. (2020), each participant rated their belief in the veracity of each statement on a 100-point scale (0certainly false; 50 -unsure; 100 -certainly true). For false (true) statements, an answer was considered correct if the participant answered less than (greater than) 50 (Weeks, 2015).

Half the statements were true. As per much of the recent work on assessing vulnerability to misinformation, for each of the 14 true and 14 false statements, half were selected with the intention that they would support partisan beliefs of Biden supporters, the other half were biased toward Trump supporters (Pennycook \& Rand, 2019; Tappin et al., 2020). See Supplemental Information (SI) A for a description of each question. The questions varied in difficulty, but none were extremely easy or difficult; the question with the highest (lowest) accuracy rate was $81.3 \%$ (19.5\%)-see SI A for details.

\subsection{2 | Demographics}

Participants were given the option to denote their age and gender identity.

\subsection{3 | Well-being}

Participants were asked to complete various measures of mental wellbeing.

\section{Depressive symptoms}

Depressive symptoms over the last 14 days were measured using the 16-item quick inventory of depressive symptomology-QIDS (Rush et al., 2003). The measure asks several multiple-choice questions about an individual's experience with depressive symptoms over the last 7 days (e.g., how well have you slept, been able to concentrate, been able to eat, ...). A meta-analysis of QIDS found it has good concurrent validity with many other measures of depressive symptoms as well as high internal consistency (Reilly et al., 2015). In this study, QIDS showed good internal consistency $(\alpha=.875)$.

\section{Affect over the last 7 days}

Negative and positive affect over the last 7 days were measured using the 20-item Positive and Negative Affect Schedule-PANAS (Watson et al., 1988). The participant answered how often they have felt 10 positive and 10 negative emotions over the last 7 days (e.g., distressed, upset, excited, proud...). For each emotion, the participant responded on a 5-point Likert scale (very slightly or not at allextremely). PANAS has high congruent validity for measuring two factors: negative affect (NA) describes the amount of unpleasurable engagement with the environment, while positive affect (PA) describes the amount of pleasurable engagement with the environment (Crawford \& Henry, 2004). While both PANAS NA and PA tend to correlate to depressive symptoms, there is still divergent validity (Crawford \& Henry, 2004; Vera-Villarroel et al., 2017; Watson et al., 1988). In this study, negative affect (PANAS NA) had good internal consistency ( $\alpha=.883$ ), while positive affect (PANAS PA) had excellent internal consistency $(\alpha=.908)$.

\section{Momentary affect}

Given that (a) transient, experimentally manipulated emotions have been shown to bias truth assessment (Weeks, 2015), and (b) wellbeing is often delineated along the continuum of state and trait affect (Tov, 2018), this study considered the effects of several momentary measures of affect. This was juxtaposed to PANAS which measured the amount one felt emotions over the last 7 days. The momentary 
affective measures included four questions, and asked how (a) happy, (b) excited, (c) depressed, and (d) anxious the participant felt "right now" (scale: -100 to 100 with extreme labels such as "extremely unhappy" and "extremely happy").

\section{Eudaimonic well-being}

Eudaimonic well-being represents the ability to pursue our potential and is often separated from measures of hedonic/subjective well-being (Ryff et al., 2021). Eudaimonic well-being was assessed using the 18-item questionnaire of Psychological Well-being (Ryff \& Keyes, 1995). For each question, the participant denoted how much they agreed with a statement on a 7-point Likert scale (strongly disagree-strongly agree). The measure includes questions about one's subjective feelings of autonomy (the ability to act independently and resist social pressures), environmental mastery (the extent to which one feels in control of one's environment), personal growth (one's sense of growth and self-improvement), positive relations (has positive and trusting relations with others), purpose in life (sense that life has meaning), and self-acceptance (positive attitude about the self) (Ryff \& Keyes, 1995). The measure has been shown to have divergent validity with hedonic/subjective measures of well-being (Keyes et al., 2002). The six-factor loading of the 18-item version has shown poor internal consistency (van Dierendonck, 2004). In such cases a single-factor is recommended (Ryff \& Keyes, 1995; van Dierendonck, 2004). This study used the single-factor model of eudaimonic well-being since poor internal consistency was found for the six-factor model. The one factor model demonstrated good internal consistency $(\alpha=.854)$.

\section{Momentary optimism}

Optimism is an aspect of well-being which does not fall cleanly within either hedonic or eudemonic well-being; however recent work has shown that it falls more in line with hedonic well-being (Gallagher \& Lopez, 2009). Given this, an "in-the-moment" assessment of optimism was included. Participants were asked how optimistic they were about the future right now (-100: extremely pessimistic and 100: extremely optimistic).

\section{Self-esteem}

Given that low self-esteem is associated with information avoidance (Howell \& Shepperd, 2016; Wiersema et al., 2012), it was hypothesized that low self-esteem could be associated with biases in truth assessment. A one-item measure of self-esteem was included (Robins et al., 2001). Participants responded to the statement "I have high self-esteem" on a 7-point Likert scale (strongly disagree-strongly agree). The measure has been shown to have strong convergent validity with longer measures of self-esteem (Robins et al., 2001).

\subsection{4 | Interpersonal factors}

To analyze whether interpersonal factors were associated with the ability to judge the veracity of political statements, several interpersonal factors were considered.

\section{Need to belong}

One's need to belong was assessed using a validated, one-item question (Nichols \& Webster, 2013). Participants used a 7-point Likert scale (strongly disagree-strongly agree) to denote how much they agreed with the statement, "I have a strong need to belong." The measure has been found to have good concurrent validity, construct validity, and test-retest reliability (Nichols \& Webster, 2013).

\section{Generosity and in-group bias}

Since generosity has been linked to a general trusting nature (Bekkers, 2007; Chaudhuri \& Gangadharan, 2007), it was hypothesized that generosity might be associated with a tendency to believe most political statements. Further, it was hypothesized that the tendency to give preferential treatment to ingroup members might be associated with a willingness to believe political congruent information. The Dictator game (Engel, 2011) has been used to measure both generosity and in-group bias in political settings (Fowler \& Kam, 2007; Rand et al., 2009; Whitt et al., 2021). This study used an incentivecompatible version of the Dictator game to measure both generosity and in-group preference. Participants were told that if they completed a post-election survey, they would be entered into a raffle to win $\$ 100$ and play a Dictator game with another randomly selected participant. They were then told that if they won the lottery a random recipient would be selected, and they could give any amount of the $\$ 100$ to that recipient. Participants were asked how much they would give an individual if the recipient (a) voted for the participant's preferred candidate, (b) voted for the other main party, (c) voted for a third-party candidate, (d) did not vote, or (e) did not divulge who they voted for. Generosity was measured as the average amount given to all five options. In-group bias was measured as the amount the winner would give to a recipient who shared their candidate minus the amount given to a recipient who voted for the other main candidate (Rand et al., 2009). Of the 338 participants who completed the postelection survey, a random dictator and a random recipient were selected. The voting behavior of the recipient was considered against the dictator's pre-election decisions, and the recipient was given part of the $\$ 100$ based on the dictator's desire. The dictator received the rest of the money.

\section{Homogeneity of social networks}

Political homophily was measured by asking participants the percentage of their friends who were aligned with various political parties. Participants answered the question: "What percentage of your friends are (a) Republican, (b) Democrat, (c) Moderate, and (d) Other." Answers to the four questions had to sum to 100 . Since it was hypothesized that biased truth assessment would be associated with political homophily, during the analysis I considered the percentage of friendships which shared the participant's political ideology.

\section{Threats of ostracism}

It was hypothesized that a participant would be more willing to believe positive statements about a friend's candidate, if the 
participant felt that the friendship would be impacted by the result of the election. To explore this, a novel series of questions was invented. Participants answered four questions about how the election result would impact their friendships. They were asked to predict how much it would affect their friendships ( -100 : extremely negatively; 100: extremely positively) with those who did or did not share their candidate if the individual's preferred candidate won or lost. A question was asked for every combination of whether the friend supported a congruent (congruent vs. incongruent) presidential candidate compared to the participant, and whether the participant's preferred candidate won (won vs. lost).

\subsection{5 | Political beliefs}

Individual differences in political and partisan beliefs were assessed with several questions. Participants were asked who they hoped would win the presidential election (Biden, Trump, Other, and I'm undecided). Participants rated their social and economic conservatism on a 7-point Likert scale (1: extremely liberal; 7: extremely conservative). Participants then described the importance of this presidential election compared to other presidential elections ( -100 : way less important; 100: way more important).

\subsection{6 | Other measures}

A few other measures were taken, but not considered in the analysis. After judging the veracity of the 28 political statements, participants were asked to guess their accuracy rate $(0-100 \%)$ and the percentage of participants who scored worse than they did $(0-$ 100\%). Participants also predicted how they would feel 2 weeks after the election if either Trump or Biden won. Finally, participants were asked how likely they thought it was that Trump would win the election.

\section{$2.4 \mid$ Procedure}

Five hundred participants completed the online questionnaire. Prior to starting, participants completed a consent form and acknowledged that they understood that they could withdraw at any time. Upon agreeing to proceed, participants answered the demographic questions. Next, they completed several measures of well-being and interpersonal factors (in order: in-the-moment affect, QIDS, psychological well-being, need to belong, and PANAS). Then, they answered severa questions about their political beliefs (social and economic conservatism, percentage of friends who support each candidate, and importance of the election). Participants then guessed the veracity of 28 political statements. Next, participants were asked to predict how well they did, and to predict how they would feel if Trump or Biden won the election. Participants then described how their friendships would be affected if Trump or Biden won the election. Finally, the participants completed the Dictator game and were told they would be paid within $24 \mathrm{~h}$.

\section{5 | Design}

Basic Pearson correlations were run to test whether accuracy in judging the veracity of political statements was associated with interpersonal factors, well-being, and political ideology. Four different calculations of accuracy were considered. Each participant's accuracy was assessed on (a) all 28 statements, (b) the false statements, (c) the true statements, and (d) discernment. As per Batailler et al. (2021), discernment was calculated as the $z$-score of the fraction of true items rated as true, minus the $z$-score of the false items rated as true.

In order to take a precautionary approach to analysis, and to reduce the risk of false positives (i.e., Type I errors), all $p$-values were Bonferroni corrected (Holm, 1979). Since there were 22 different individual measurements, each $p$-value was multiplied by 22 . In terms of the assumptions of Pearson correlations, it has been shown that the present sample size $(N=477)$ is likely large enough that the assumption of normality is met due to the Central Limit Theorem (Lumley et al., 2002). However, as an extra precaution, $95 \%$ bootstrapped confidence intervals were calculated, as bootstrapped confidence intervals do not assume normality (Wright et al., 2011). While the relationships between the variables were broadly linear (graphs discussed below), to verify that small failures in the assumptions of linearity and outliers were not skewing the results, a non-parametric Spearman correlation was run for each comparison. Spearman correlations have been shown to be more robust to outliers (Bishara \& Hittner, 2014). Further, while the relationships between the variables were broadly linear, Spearman correlations only assume a monotonic relationship, and, as discussed below, the comparisons had broadly monotonic relationships.

While it is important to consider each of the measures in isolation, it is also vital to understand how the factors relate and to understand which combination of factors best predict truth assessment of political headlines. The best subset selection algorithm was used to analyze the combination of factors which predict accuracy in judging the veracity of political statements. Best subset selection finds the best multiple regression model while reducing the risks of overfitting by using cross-validation (Gómez \& Prokopyev, 2021; Hastie et al., 2001; James et al., 2013). A detailed description of best subset selection is given below.

\section{$3 \mid$ RESULTS}

Table 1 shows the results of the Pearson correlations. A Pearson correlation was run for each individual measurement and four different measures of accuracy: (a) Overall (fraction correct for all 28 statements), (b) All False (fraction of the 14 false statements correctly diagnosed as false), (c) All True (fraction of the 14 true statements correctly diagnosed as true), and (d) Discernment (z-scored fraction of 
TABLE 1 Pearson correlations between individual factors and accuracy in judging the veracity of political information.

\begin{tabular}{|c|c|c|c|c|c|}
\hline Factors & & \multicolumn{4}{|c|}{ Accuracy } \\
\hline Mental health & QIDS depressive symptoms & -.03 & $-.39^{* * *}$ & $.37^{* * *}$ & -.02 \\
\hline \multirow[t]{2}{*}{ State affect ( 7 days) } & PANAS Negative Affect (7 days) & -.03 & $-.56^{* * *}$ & $.55^{* * *}$ & -.01 \\
\hline & PANAS Positive Affect (7 days) & .00 & $-.28^{* * *}$ & $.29^{* * *}$ & .01 \\
\hline \multirow[t]{3}{*}{ Momentary affect } & Happy & -.03 & $-.30^{* * *}$ & $.28^{* * *}$ & -.02 \\
\hline & Depressed & -.01 & $-.32^{* * *}$ & $.32^{* * *}$ & .00 \\
\hline & Anxious & -.06 & $-.41^{* * *}$ & $.37^{* * *}$ & -.05 \\
\hline Eudaimonic & Ryff's Psychological well-being & -.00 & $.41^{* * *}$ & $-.42^{* * *}$ & -.01 \\
\hline Other well-being & Optimistic for future & -.01 & $-.24^{* * *}$ & $.23^{* * *}$ & -.01 \\
\hline Political beliefs & Election importance & .03 & .12 & -.10 & .03 \\
\hline \multirow[t]{8}{*}{ Interpersonal } & Generosity & -.03 & $-.59^{* * *}$ & $.58^{* * *}$ & -.01 \\
\hline & Ingroup bias & .02 & .00 & .00 & .02 \\
\hline & $\%$ Congruent friends & -.03 & .13 & $-.15^{*}$ & -.03 \\
\hline & Impact to congruent friend; you win & .03 & $-.22^{* * *}$ & $.25^{* * *}$ & .03 \\
\hline & Impact to incongruent friend; you win & .00 & $-.41^{* * *}$ & $.42^{* * *}$ & .01 \\
\hline & Impact to congruent friend; you lose & -.03 & $-.44^{* * *}$ & $.43^{* * *}$ & -.02 \\
\hline & Impact to incongruent friend; you lose & -.07 & $-.51^{* * *}$ & $.47^{* * *}$ & -.05 \\
\hline & Need to belong & -.02 & $-.24^{* * *}$ & $.22^{* * *}$ & -.01 \\
\hline
\end{tabular}

Note: Four measures of accuracy are presented. They represent the accuracy rate for: (a) all 28 news items (overall), (b) the 14 false statements (all false), (c) the 14 true statements (all true), and (d) the z-scored fraction of true statements rated as true minus the $z$-scored fraction of false statements rated as true (i.e., discernment). Each cell represents the correlation coefficient from the Pearson correlation followed by stars if the Bonferroni corrected $p$-value was significant. Categories of significance were signified with stars. ${ }^{*} p<.05 ;{ }^{* *} p<.01$; and ${ }^{* * *} p<.001$.

true statements rated as true minus the $z$-scored fraction of false statements rated as true).

Before discussing the specific results, there are a couple of general trends worth noting. First, few of the factors were significantly associated with total accuracy of all 28 statements. However, this was because the relationship between individual factors and accuracy for true statements was orthogonal compared to the relationship between individual factors and accuracy for false statements. This meant the effect averaged out when considering all items (see below). Second, given the large sample size, even after Bonferroni corrections, many correlations were highly significant, so the results section focuses on effect sizes. Third, many of the individual factors were correlated to various degrees. Supplemental Information (SI) B depicts the correlation matrix of the individual factors; pertinent aspects are discussed throughout the results.

Lastly, given space constraints, bootstrapped 95\% confidence intervals for the Pearson correlation coefficients are included in Supplemental Information C (see Table C1). Additionally, the Spearman correlations and bootstrapped confidence intervals are also found in Supplemental Information C (see Tables C2 and C3, respectively). The bootstrapped confidence intervals and Spearman correlations were aligned with the results from the Pearson correlations. At no point was one calculation significant, while the other was not. Further, the correlation coefficients (i.e., the effect sizes) between the Pearson and Spearman correlations only slightly varied. This suggests that any subtle violations in the assumptions of the Pearson correlations were not enough to dramatically skew the results. As such, the discussion of the analysis focuses on the Pearson correlations.

\section{1 | Interpersonal measures}

Interpersonal factors had some of the largest associations with accuracy in judging political statements. In general, if an individual was prosocial or the election dramatically affected their friendships, then they were more likely to be vulnerable to believing false information. Generosity in the dictator game was largely, positively correlated with individual accuracy for true statements $(r=.58)$, but highly negatively correlated with individual accuracy for false $(r=-.59)$ statements ( $p$ values are shown in Table 1 and bootstrapped 95\% confidence 

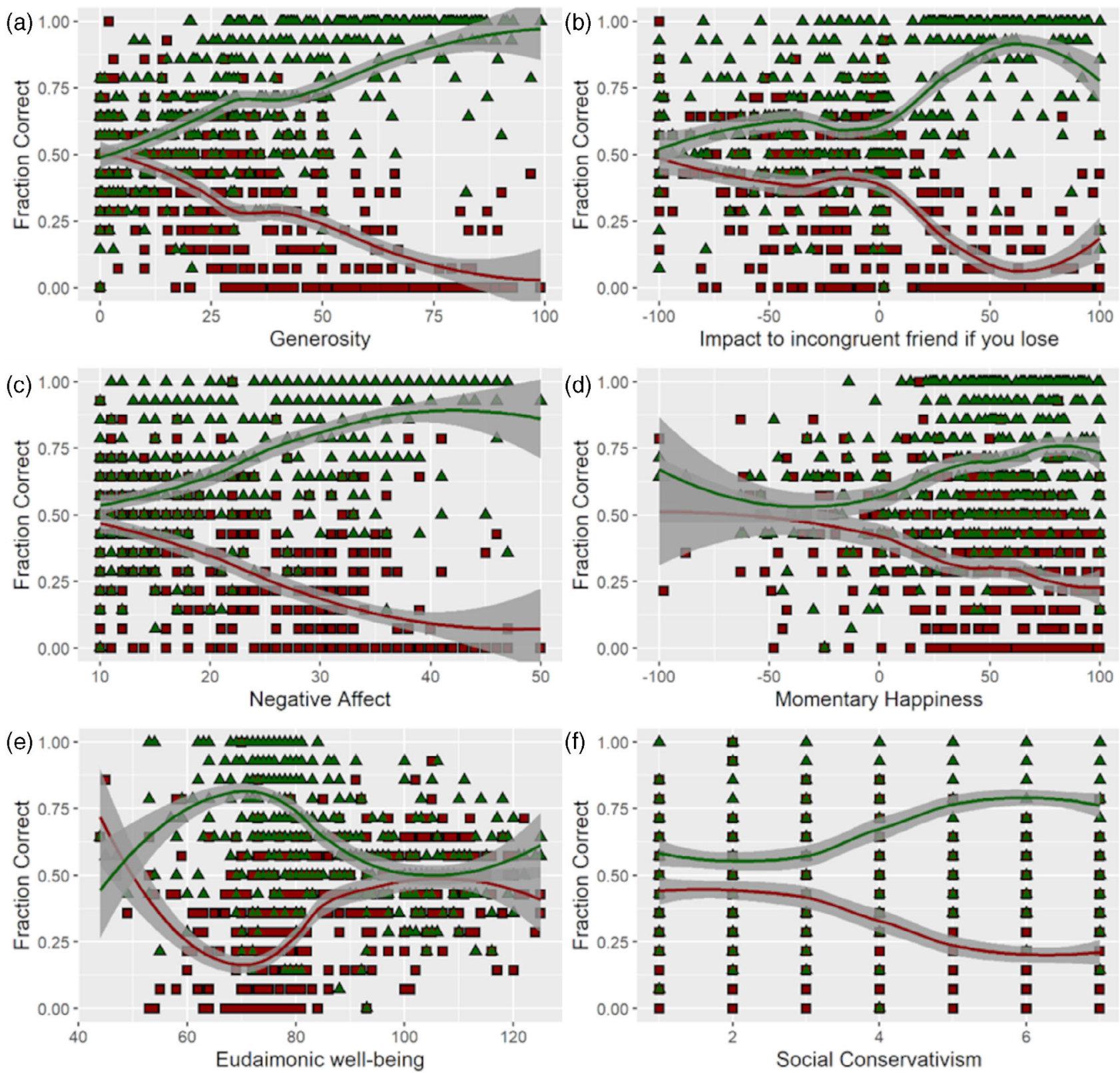

$\triangle$ True Statements

Social Conservativism

False statements

FIGURE 1 Each graph depicts the association between an individual factor ( $x$-axis) and the fraction of news articles answered correctly ( $y$-axis). Each graph illustrates how accuracy for the 14 true statements (green triangles) and the 14 false statements (red squares) was associated with an individual factor. Each curve represents the best locally estimated scatterplot smoothing (LOESS) curve. Shaded areas represent $95 \%$ confidence bands. (a) Generosity measured as the average amount given in the Dictator game. (b) The impact to a friendship if the friend supports the opposing candidate, and the participant's candidate loses (-100: extremely negative; 100: extremely positive). (c) negative affect over the last 7 days; larger values represent increased negative affect. (d) In-the-moment happiness (-100: extremely unhappy; 100 extremely happy).

(e) Eudaimonic wellbeing (larger values represent a sense of autonomy and that life has meaning). (f) Social conservatism (1: extremely liberal; 7: extremely conservative).

intervals for all correlations can be found in Table C1 of Supplemental Information C). Of all the factors considered in this work, generosity represents the largest effect. Figure 1 a illustrates this. Those who are generous to others are more likely to be accurate for true statements, but inaccurate for false headlines. This is because generous individuals predicted most of the statements to be true. Looking at
Figure $1 a$, if an individual is not generous (i.e., does not give money in a Dictator game), then the best smoothed fit curve predicts that the individual will attain an accuracy rate of $50 \%$. This means that, if one gives no money, then generosity offers no information about an individual's ability to assess the veracity of news; the average performance of ungenerous individuals is $50 \%$. However, as 
generosity increases, it is clear that assessment of the veracity of headlines is biased. Further, considering Figure 1a, the effect of generosity is clear even for those who are only a little generous. Those who, on average, offered $25 \%$ (50\%) of their potential winnings to others, scored $66 \%$ (75\%) for true statements, but only $35 \%$ (25\%) for false statements.

Those who felt that their friendships were vulnerable enough to be impacted by the election, were more vulnerable to false information. If an individual thought that their candidate losing the election would improve their friendships with those supporting the other main candidate (i.e., incongruent friendship), then they were more likely to believe that most statements were true. Consequently, they scored higher for true statements $(r=.47)$, but lower for false statements $(r=-.51)$. Figure 1b illustrates the effect; this was the third largest effect for all the correlations. Slightly smaller but similar effects were found if (a) incongruent friendships would be improved if the participant's candidate won (true: $r=.42$; false: $r=-.41$ ), or (b) congruent friendships would be improved if the participant's candidate lost (true: $r=.43$; false: $r=-.44$ ). Only small-moderate effects were found for the impact on congruent friendships if the participant's candidate won (true: $r=.25$; false: $r=.22$ )

Need to belong had a small-moderate association with assessing the veracity of headlines. An increased need to belong was associated with a general inclination to believe statements were true, leading to better accuracy for true statements $(r=.22)$, but worse performance for false statements $(r=-.24)$. Homogeneity of social networks (measured as the percentage of friends who shared one's political alignment) weakly predicted lower accuracy for true statements ( $r=-.15)$, but, after Bonferroni correction, it was not significantly related to higher accuracy for false statements $(r=.13)$. Lastly, the difference in generosity between congruent and incongruent recipients (a measure of in-group bias), had little association with accuracy rates (see Table 1). Scatter plots of every factor considered in this work can be found in SIC.

\subsection{Negative affect and mental-health factors}

In general, poor mental well-being was associated with believing both true and false information, and thus poor mental well-being was associated with a vulnerability to misinformation (i.e., false information). Negative affect over the last 7 days (as measured by PANAS) was associated with higher accuracy for true statements $(r=.55)$, but lower accuracy for false statements $(r=-.56)$. These were the second largest effect sizes; second only to the interpersonal factor, generosity. Figure 1c illustrates that the bias in accuracy was driven by those struggling with negative affect. The average score of those with low levels of negative affect was approximately $50 \%$ for both true and false statements. However, increased negative affect was associated with a willingness to believe most statements. The effect was quite large even for those who were only feeling small to moderate amounts of negative affect. Considering Figure 1c, a measure of 20 (30) meant that, on average, if an individual felt "a little" ("moderate") negative affect over the last 7 days, then, on average, they answered $65 \%$ (81\%) of the true statements correctly and $35 \%$ $(18 \%)$ of the false statements correctly.

Similarly, depressive symptoms over the last 14 days were associated with higher accuracy for true statements $(r=.37)$ but lower accuracy for false statements $(r=-.39)$. Further, momentary measurements of anxiety and depression were associated with higher accuracy for true statements ( $r=.37, r=.32$, respectively) and lower accuracy for false statements $(r=-.41, r=-.32$, respectively). See SI $C$ for visualizations.

\section{3 | Positive affect}

There is evidence that positive affect is not the inverse of negative affect (Schmukle et al., 2002). This was the case here, as PANAS negative affect was not correlated to PANAS positive affect $(r=.02)$ or momentary happiness ( $r=-.05)-$ see SI B. Somewhat surprisingly, the effects of positive affect were in the same direction as negative affect, although the effects were smaller. Positive affect over the last 7 days was associated with higher accuracy for true statements $(r=.29)$ and lower accuracy for false statements ( $r=-.28)$. In-themoment measures of happiness showed similar associations (true: $r=.28$; false $r=-.30$ ). Figure $1 \mathrm{~d}$ illustrates this; other than a few outliers who were deeply unhappy, unhappiness was not particularly predictive of accuracy for true or false statements. However, as happiness increased, the individual was more willing to believe both true and false statements.

The fact that both negative and positive affect predict biased beliefs in the same direction is corroborated by the work of Martel et al. (2020), suggesting that heightened emotions bias truth assessment. This narrative might explain the moderate-large effect of momentary excitement. Those with higher levels of excitement, were more accurate when analyzing true statements $(r=.42)$, but less accurate when analyzing false statements $(r=-.45)$. Excitement, however, is not necessarily an unambiguously "positive" emotion, as it was positively correlated to both negative $(r=.33)$ and positive $(r=.53)$ affect (see SI B).

\subsection{Eudaimonic well-being}

Similar to the results found with negative affect, those with lower levels of eudaimonic well-being were consistently more accurate in diagnosing true statements, but less accurate in diagnosing false statements (true: $r=-.42$; false: $r=.41$ ). Figure 1e illustrates the effect of eudaimonic well-being. Those with a high sense of eudaimonic wellbeing (i.e., those who felt autonomous and positive about life) averaged a score of approximately $50 \%$. However (other than a few outlying participants who had very low scores) lower scores were associated with biases in accuracy. Of note, Figure 1e shows that eudemonic well-being might be the only comparison which does not show a monotonic relationship with accuracy. While it seems there 
are only a few outliers with low eudaimonic well-being who are causing the relationship to appear parabolic (i.e., the relationship is monotonic when eudaimonic well-being is greater than 65), these might skew the results of the Spearman and Pearson correlations.

\subsection{Other well-being}

There were moderate-small effects of one's optimism for the future (true: $r=-.24$; false: $r=.23$ ). There was no significant effect of selfesteem on the accuracy of judging the veracity of political statements (see Table 1).

\section{6 | Political beliefs and demographics}

Biased assessment was associated with both higher social (true: $r=.39$; false: $r=-.42$ ) and economic (true: $r=.27$; false: $r=-.30$ ) conservatism. Figure $1 \mathrm{f}$ illustrates that social liberalism is not very predictive of accuracy rates. However, those with high levels of social conservatism tend to believe most statements, leading to high accuracy for true statements, but low accuracy for false statements. The effect of the importance of the election was not significant. The effects of age were relatively small (see Table 1 and SI C for visualizations).

\section{7 | Discernment}

The term "discernment" is used in signal theory to describe the difference between the $z$-scored fraction of instances where an individual thought true headlines were true minus the $z$-scored fraction of instances where an individual thought false headlines were true (Pennycook \& Rand, 2021). Table 1 denotes the relationship between discernment and each factor. In general, few of the factors were associated with discernment (see Table 1).

\section{8 | Partisan bias}

Until now, the analysis has focused on all true or false statements, even though half of the statements were aligned with liberal ideology and half with conservative ideology. There is robust evidence that individuals are more likely to believe information that supports their partisan beliefs (Anthony \& Moulding, 2019; Bago et al., 2020; Pennycook \& Rand, 2021; Vegetti \& Mancosu, 2020). However, little is known about how well-being and interpersonal factors interact with partisan biases when assessing political information. To consider the effects of individual differences on partisan biases, the true and false statements were separated into four groups based on participant's preferred candidate: (a) true statements which were congruent with the partisan beliefs of the participant, (b) true statements which were incongruent, (c) false congruent, and (d) false incongruent. This meant that, for each information type, different questions were being considered for Trump compared to Biden supporters. For example, the false statement "Trump claimed that, prior to the pandemic, the Trump administration was reducing the national debt. Was Trump's statement true?," would be considered false, congruent for Trump supporters, but false, incongruent for Biden supporters.

On average, individuals showed a large (and statistically significant: $p<.001)$ partisan bias. Individuals were much more likely to believe false statements that supported their ideology and thus scored poorly (20.2\%) compared to the average accuracy rate of false, incongruent statements (41.8\%). Individuals were also much more likely to believe true statements that supported their ideology (78.0\%) compared to those supporting the other party (59.3\%). See Figure D1 for more details.

Partisan bias for false (true) statements was measured by subtracting individual accuracy rates for false (true) incongruent statements from false (true) congruent statements. If individuals tended to believe statements that were congruent with their beliefs, then, for false (true) statements, they would receive lower (higher) accuracy rates for congruent compared to incongruent statements. Thus, for false (true) statements, a partisan bias would be represented as a negative (positive) value.

Since generosity, high negative affect and poor eudaimonic wellbeing were all associated with believing most statements, these individuals, on average, did not display much of a partisan bias. Interestingly, however, those on the other end of the spectrum (low generosity, low negative affect and high eudaimonic well-being) displayed a large partisan bias. Figure 2 illustrates this. A Pearson correlation showed that as generosity increased, partisan bias decreased for both true $(r=-.38, p<.001)$ and false statements $(r=.35, p<.001)$. The same was found for negative affect (true: $r=-.39, p<.001$; false: $r=.37, p<.001$ ) and eudaimonic well-being (true: $r=.36$, $p<.001$; false: $r=-.30, p<.001$ ). Further, a weaker effect was found for in-the-moment happiness (true: $r=-.20, p<.001$; false: $r=.26$, $p<.001$ ). As negative affect decreased and eudaimonic well-being increased, individuals tended to display a larger partisan bias (see SI D for a complete statistical analysis of each of the individual factors, including Pearson correlations, Spearman correlations, and bootstrapped confidence intervals).

Until now, the analyses showed that those with low generosity, low negative affect, and high eudaimonic well-being were unbiased in how they assessed headlines. However, they actually displayed a partisan bias which averaged out to $50 \%$ accuracy across all true (and false) statements. Those with high generosity, high negative affect, and low eudaimonic well-being showed little partisan bias, as these individuals were more likely to believe all headlines, regardless of their partisan ideology.

These results hold for almost every factor measured in this work (see SI D). If one extreme of the measure was associated with a bias to believe most headlines, the other extreme was associated with a partisan bias. This demonstrates that well-being and interpersonal 

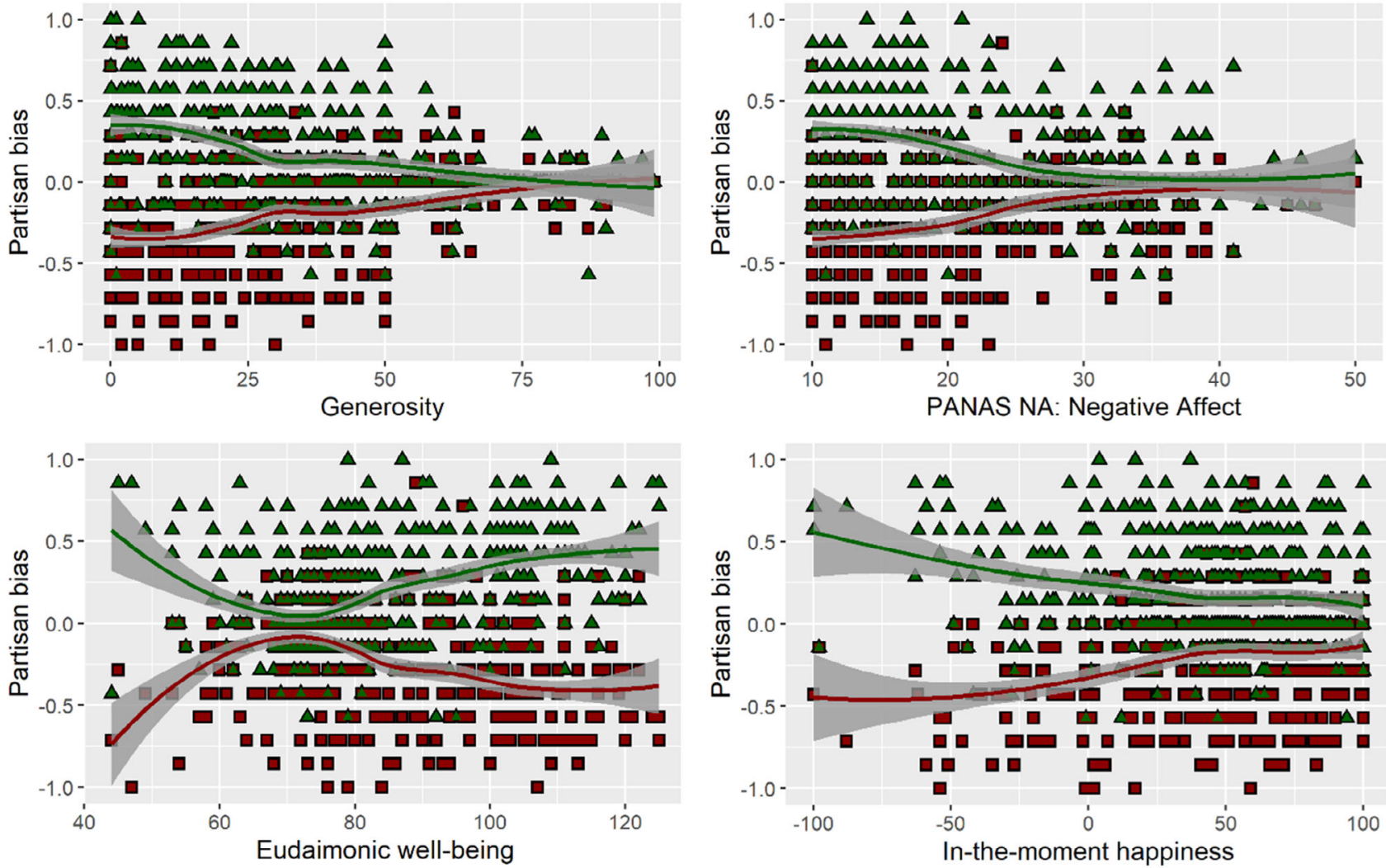

FIGURE 2 Association between partisan bias and individual factors. Partisan bias is the accuracy rate for congruent headlines minus incongruent headlines. Green triangles (red squares) represent the partisan bias for true (false) statements. For true (false) statements, values greater (lower) than zero represent partisan bias (a tendency to believe congruent headlines more than incongruent headlines). Top-left: Generosity (average amount given in the dictator game). Top-right: Negative affect over the last 7 days, Bottom-left: Ryff's eudaimonic well-being (higher values are associated with a sense of autonomy and meaning). Bottom-right: In-the-moment happiness ( -100 : extremely unhappy; 100: extremely happy).

factors interact with partisan bias when individuals assess the veracity of political headlines.

\section{9 | Best subset selection}

While it is important to consider each of the measures in isolation, it is also vital to understand how the factors relate and to understand which combination of factors best predict accuracy. While large associations were found across interpersonal, well-being, and political factors, many of these factors covaried with each other (see SI B). It is possible that the variance explained by several of these factors are shared, or it is possible that including multiple variables in a model could explain an even larger amount of the variation in how individuals process political statements. Understanding which factors predict accuracy above and beyond other factors can help us better understand the most important archetypes of factors associated with difficulty assessing the veracity of information.

Importantly, while it is valuable to consider how various factors combine to predict vulnerability to biased truth assessment, analyzing models with multiple variables can be prone to overfitting, reducing the likelihood of replicability (Yarkoni \& Westfall, 2017). To reduce the likelihood of replication issues, some have suggested that psychological studies should use out-of-sample analysis techniques, where the prediction of a model is judged on its ability to predict data that was not used to fit the model (Hofman et al., 2021; Yarkoni \& Westfall, 2017). This study used the best subset selection algorithm to find the best combination of factors which predict out-of-sample data. The best subset selection algorithm was used as it generally outperforms other heuristics/sparse algorithms when trying to find the best combination of factors to predict a dependent variable (Bertsimas et al., 2016; Mazumder et al., 2011).

Best subset selection finds the best multiple regression model while reducing the risks of overfitting by using cross-validation (Gómez \& Prokopyev, 2021; Hastie et al., 2001; James et al., 2013). To find the best combination of predictors, all $p=21$ individual factors found in Table 1 were included in the analysis (with the exception of Age, which was excluded because the question was optional, and 24 participants did not answer). For each $k=[1,2 \ldots p]$, best subset selection fit a linear regression of all possible $\left(\begin{array}{l}p \\ k\end{array}\right)$ models containing exactly $k$ features. For each $k$, the model with the largest $r^{2}$ was selected and labeled: $M_{k}$. The final goal was to select the best model from $\left[M_{0}, M_{1}, \ldots M_{p}\right]$. Since the more complex models were likely 
FIGURE 3 The best models for predicting accuracy for true (top) and false (bottom) statements. The image depicts the features included in each of the best fit regression models with k parameters: $k=[1,2, \ldots 21]$. The area is black if the feature was included in the best fit model. The bottom row represents the best model when only one parameter was permitted $(k=1)$. When only one parameter was allowed, only the intercept and generosity were included for both true and false statements. The row second from the bottom represents the best model when two parameters were permitted $(k=2)$. For both true and false statements, generosity and PANAS NA (negative affect) were included. The $y$-axis represents the variance explained by the model after running multiple regression $\left(r^{2}\right)$.
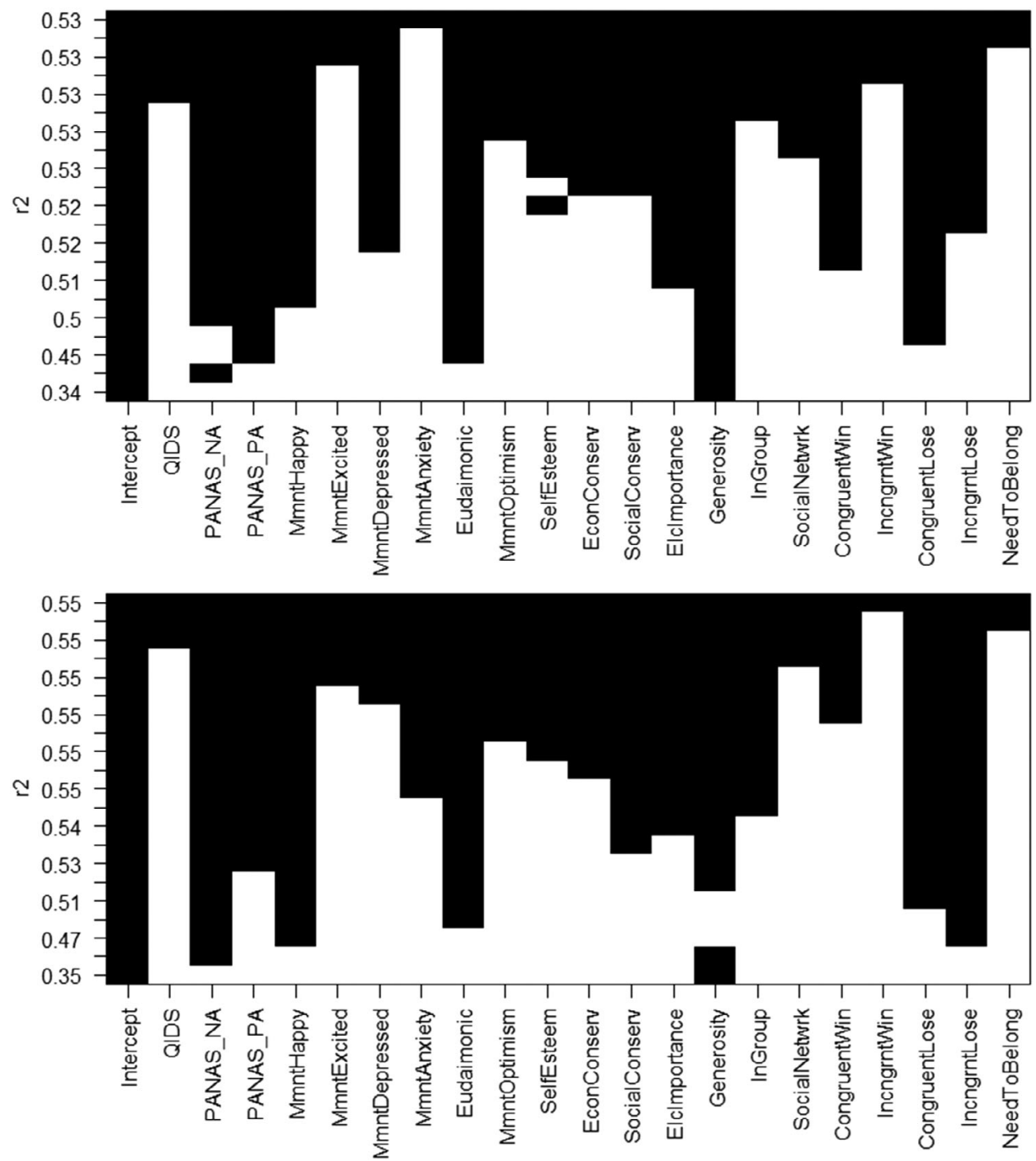

overfit, 10-fold cross-validation was used to find the average root mean squared-error (RMSE) for out-of-sample data for each $M_{k}$. The model with the lowest average RMSE can be considered the best model at predicting out-of-sample data (though one still might choose a less complex model, see below). For details on how best subset selection outperforms other model selection algorithms, see SI E.

\subsection{1 | True statements}

Best subset selection was run to find the parameters which best predicted accuracy for true statements. The best model for each value of $k$, is shown in Figure 3(top). The best fit model with only one parameter $(k=1)$ included generosity in the Dictator game. Since $r^{2}$ necessarily increases as the complexity of the model increases, 10-fold cross-validation was used to test the out-of-sample prediction error for each of the models in the set $M_{k}$. Figure 4 illustrates the average root mean squared error (RMSE) for each model after repeating 10-fold cross validation 100 times. The lowest RMSE involved a model with 10 features. This suggested that models with 11 features or more were overfit. However, many of the models with 7-10 features did not explain much more variance (i.e., the effect sizes are

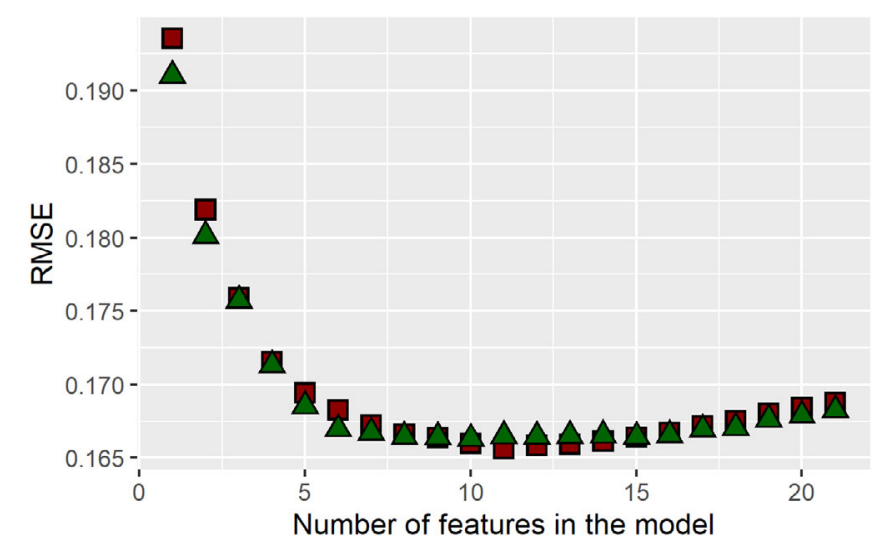

FIGURE 4 The out-of-sample root mean squared error (RMSE) for each of the best models with $k$ parameters after running 10 -fold cross-validation 100 times. Red squares (green triangles) represent the models predicting accuracy for false (true) statements. The lowest RMSE for false (true) statements is 11 (10) parameters.

small). For parsimony and brevity, I only discuss models which explained at least $1 \%$ more of the variance by adding one additional feature. 
$M_{1}$ only included generosity in the Dictator game. This explained $33.9 \%$ of the variance. $M_{2}$ explained $41.5 \%$ of the variance and included both generosity and negative affect over the last 7 days (as measured by PANAS NA). $M_{3}$ showed that the first three most important variables included eudaimonic well-being (Ryff's scale), hedonic well-being (PANAS PA), and interpersonal (generosity) factors. The model explained $44.6 \%$ of the variance. Adding features continued to improve the variance explained by at least $1 \%$ until six features were added. The final model with six features explained $50.7 \%$ of the variance. The model included two interpersonal measures (generosity and the impact on congruent friendships if the participant's candidate lost), Ryff's measure of eudaimonic well-being, and three hedonic well-being measures (PANAS NA, PANAS PA, and momentary happiness). Since hedonic well-being, eudaimonic wellbeing, and interpersonal factors continued to explain variance above and beyond simpler models, we can be confident that all three types of features are important in predicting accuracy rates.

Importantly, there were several variables with moderate correlations that were not included in the best subset selection model. Best subset selection allows us to analyze why this may be. Many of the factors considered in this work are correlated with other factors. If a variable with a large association was not included, this is likely because the variance that the factor explained had already been explained by another factor. For example, depressive symptoms (QIDS) were associated with accuracy in true statements ( $r=-.37$, but the measure was not included in the model until 17 parameters were involved and the model was overfit. However, depressive symptoms were highly correlated with negative affect $(r=.64$; see Table B1 in SI B) and inversely correlated to eudaimonic well-being $(r=-.59$; see SI B), and both negative affect and eudaimonic wellbeing were added to the model early. As such, while depressive symptoms represent an important predictor of accuracy, the variance explained by the measure is likely shared with that of negative affect and eudaimonic well-being. As a result, it was not included in the model as it did not explain accuracy above and beyond that of negative affect and eudaimonic well-being.

\subsection{2 | False statements}

Best subset selection was run on 21 features to select the best model for predicting accuracy for the false political statements. Figure 3(bottom) illustrates the features chosen for each model, $M_{K}$. 10-fold cross validation was repeated 100 times and the lowest RMSE was found when including 11 features (see Figure 4). Again, for parsimony and brevity, a model is only discussed if adding a feature improved $r^{2}$ by at least .01 (i.e., explained an additional 1\% of the variance).

As with true statements, $M_{1}$ only contained generosity and explained $35.2 \%$ of the variance $\left(r^{2}=.352\right) . M_{2}$ explained $43.1 \%$ of the variance and contained both generosity and negative affect over the last 7 days (as measured by PANAS NA). Adding factors continued to improve the variance explained by at least $1 \%$, until five factors were included. This model explained $51.3 \%$ of the variance, and, as with true statements, included interpersonal, hedonic well-being, and eudaimonic well-being measures. $M_{5}$ included two hedonic well-being features (momentary happiness and negative affect), Ryff's measure of eudaimonic well-being, and two interpersonal features (if your candidate loses the election, how will it impact friendships that share and do not share the participant's candidate).

Of note, at first glance it may seem confusing that generosity is the best predictor when only one factor is included in the model, but it disappears between $M_{3}$ and $M_{6}$. This is likely because generosity in the Dictator game is a heterogeneous concept. Considering the correlation matrix (see Table B1), generosity was highly correlated to both negative affect $(r=.55)$ and interpersonal factors such as the impact to incongruent friendships if the participant's candidate loses $(r=.57)$. It was also moderately inversely correlated to eudaimonic well-being $(r=-.34)$. When there was only one variable in the model, generosity likely pulled the weight of hedonic well-being, eudaimonic well-being, and interpersonal factors. But when multiple variables were added, hedonic well-being, interpersonal, and eudaimonic well-being measures were included since each type of factor explained different variation.

\subsection{0 | The disappearing effects of social and economic conservatism}

The best-subset analysis offers important insight into the effects of social and economic conservatism. We know from this and other studies that conservatism is associated with poor judgment in the veracity of political statements (Garrett \& Bond, 2022; Pennycook \& Rand, 2019, 2021). In this study, despite decent effect sizes for social and economic conservatism (see Table 1), neither measure of conservatism was included in a best subset selection model that explained more variance for either true or false statements. This suggests that conservatism qua ideology may not be the driving force in previous work. Considering the correlation matrix in SI B, both social and economic conservatism were correlated to measures of hedonic well-being. Social conservatism was correlated to PANAS negative affect $(r=.35)$ and happiness $(r=.34)$. Similarly, economic conservatism was correlated to PANAS negative affect $(r=.23)$ and happiness $(r=.35)$ This is supported by previous work that has found that conservatives experience more happiness (Wojcik et al., 2015), but also emotionally react more strongly when faced with negative events (Joel et al., 2014). Since conservatism was not added to the best subset selection models until after the above measures, and, when it was added, it did not explain much additional variance, this suggests that the main driving forces linking conservatism and biased truth assessment may be related to conservatism qua aspects of wellbeing rather than conservatism qua ideological beliefs.

To explore this further, two different analyses were run. First, hierarchical regression was used to test whether conservatism continued to explain accuracy rates when controlling for negative affect and happiness. Second, mediation analysis was conducted to see whether 
hedonic well-being mediated the effect of conservatism when predicting accuracy rates.

\subsection{1 | Hedonic well-being mediates social conservatism}

When considering true statements, a linear regression showed that social conservatism explained $15.0 \%$ of the variance when predicting accuracy rates, $F(1,475)=83.5, b_{1}=0.44, p<.001, r^{2}=0.150$. Most of this explanatory variance disappeared when controlling for negative affect (PANAS NA) and momentary happiness. A regression with negative affect and momentary happiness explained $39.6 \%$ of the variance when predicting accuracy for true statements, $F(1,475)=155.5$, $b_{\text {na }}=.13, b_{\text {happy }}=.002, p<.001, r^{2}=.396$. If social conservatism was added to the regression with negative affect and happiness, then all three variables explained $40.5 \%$ of the variance. So after controlling for negative affect and happiness, social conservatism only explained an extra $0.9 \%$ of the variance; this is in sharp contrast to the $15 \%$ when not controlling for hedonic well-being. Given this, it is possible that hedonic well-being was mediating the effect of social conservatism when predicting accuracy rates for true statements.

Parallel mediation analysis was run to test whether negative affect and happiness mediated the effect of social conservatism when predicting the accuracy rates of true statements. Parallel mediation with bootstrapped confidence intervals showed that there was a significant indirect effect of negative affect $(b=.21,95 \% \mathrm{Cl}[.015, .026]$, $p<.001)$ and happiness ( $b=95 \% \mathrm{Cl}[.007, .014], p<.001)$. Since there was a significant indirect effect for both variables, and since this was verified in that the bootstrapped confidence intervals did not cross zero, this provides evidence for a mediating effect (Memon et al., 2018). In this case, both negative affect and happiness mediated the effect of social conservatism when predicting accuracy rates for true statements. While the most useful measure of effect sizes in mediation analysis have been debated, the ratio of the indirect effect to the total effect is a stable measure (Wen \& Fan, 2015). Here, 70\% of the total effect was mediated by the indirect effects of negative affect and happiness (note: for brevity, the statistics for each regression tested in mediation analysis is not given in the main text but is included in Supplemental Information F).

Next, I considered whether negative affect and happiness mediated social conservatism when predicting the veracity of false statements. A linear regression showed that social conservatism explained $17.62 \%$ of the variance when predicting accuracy rates for false statements, $F(1,475)=101.6, b_{1}=-0.48, p<.001, r^{2}=0.176$. However, after controlling for negative affect and happiness, social conservatism only explained an extra $1.47 \%$ of the variance. Given this, it was possible that hedonic well-being was mediating the effect of social conservatism when predicting accuracy rates for false statements.

Parallel mediation analysis was run to test whether negative affect and happiness mediated the effect of social conservatism when predicting the accuracy rates of false statements. There was a significant indirect effect of negative affect $(b=-.21,95 \% \mathrm{Cl}[-.027$,
$-.016], p<.001)$ and happiness $(b=-.11,95 \% \mathrm{Cl}[-.016,-.007]$, $p<.001)$. Since there was a significant indirect effect for both variables, and since this was verified in that the bootstrapped confidence intervals did not cross zero, this provided evidence that both negative affect and happiness mediate the effect of social conservatism when predicting accuracy rates for false statements. Further, $66.67 \%$ of the total effect was mediated by the indirect effects of negative affect and happiness. See SI F for a graph of all the regression coefficients used in the mediation analysis.

\subsection{2 | Hedonic well-being mediates economic conservatism}

Similar to above, I considered whether negative affect and happiness mediated the effect of economic conservatism when predicting the veracity of both true and false political statements. In terms of true statements, a linear regression showed that economic conservatism explained $7.13 \%$ of the variance when predicting accuracy rates for true statements, $F(1,475)=36.45$, $b_{1}=0.033, p<.001, r^{2}=0.071$. However, after controlling for negative affect and happiness, economic conservatism only explained an extra $0.1 \%$ of the variance. Parallel mediation analysis showed a significant indirect effect of negative affect $(b=.016$, $95 \% \mathrm{Cl}[.010, .022], p<.001)$ and happiness $(b=.13,95 \% \mathrm{Cl}[.008$, $.017], p<.001)$, suggesting that both measures of hedonic wellbeing mediated the effect of economic conservatism. Further, $84.85 \%$ of the total effect was mediated by the indirect effects of negative affect and happiness (see SI F for details).

Lastly, I tested whether the effect of economic conservatism on predicting the accuracy of false statements was mediated by negative affect and happiness. A linear regression showed that economic conservatism explained $9.22 \%$ of the variance when predicting accuracy rates for false statements, $F(1,475)=48.26, b_{1}=-0.04, p<$. $001, r^{2}=0.092$. However, after controlling for negative affect and happiness, economic conservatism only explained an extra $0.4 \%$ of the variance. Parallel mediation analysis showed there was a significant indirect effect of negative affect $(b=-.16,95 \% \mathrm{CI}[-.023,-.010]$, $p<.001)$ and happiness $(b=-.13,95 \% \mathrm{Cl}[-.018,-.009], p<.001)$, suggesting a mediation effect. Further, $76.3 \%$ of the total effect was mediated (see SI F for details).

\section{4 | GENERAL DISCUSSION}

This work found that interpersonal factors (such as generosity and the impact of the election on friendships) and low well-being (broadly speaking) were associated with a high likelihood to believe most statements. Consequently, such individuals were vulnerable to believing misinformation. The tendency for individuals to believe most statements has been referred to as the "truth bias" (Mccornack \& Parks, 1986), and has been shown in a variety of contexts (Levine et al., 1999), including when individuals judge the veracity of political 
statements (Clementson, 2017). The present work suggests that, in the political realm, the truth bias may not be a general effect. Rather, those with certain interpersonal and well-being factors may be more prone to the truth bias.

The truth bias may help explain why the effect sizes of various measures on true statements had similar effect-sizes (although in the opposite direction) compared to false statements (see Figure 1). To take an example, low generosity did not provide information on the ability to judge whether a statement was true. Figure 1a shows that the average accuracy rate for less generous individuals was (approximately) $50 \%$ for both true and false statements. However, as generosity increased, the truth bias seemed to increase. If an individual was more generous, they were predisposed to believe more statements were true. Such individuals would, on average, get more true statements correct than those without a truth bias. Further, such individuals would get a comparative number of false statements incorrect compared to those without the truth bias. Thus, for those exhibiting a truth bias, one would expect a comparable effect size for both true and false statements compared to those without a truth bias. Given this, it is important to note that, for those exhibiting a truth bias, higher accuracy in true statements is probably not associated with competence but is an artifact of being biased toward believing statements. Those with a truth bias have difficulty navigating the political landscape but happen to guess correctly on true statements. As such, the present work suggests that poor well-being and some interpersonal factors (e.g., generosity) may be risk factors for successfully navigating the political, information landscape.

This work also used best subset selection to demonstrate that interpersonal factors, hedonic well-being, and eudaimonic well-being were not all explaining the same, shared variance. By including a few interpersonal, eudaimonic well-being, and affective factors, over $50 \%$ of the variance was explained for both true and false statements. Further, these models were likely not overfit, given their performance in out-of-sample prediction. This shows that predicting accuracy when judging political information is multi-faceted, but perhaps not as multi-faceted as previously thought. About $50 \%$ of the variation could be explained with a few well-being and interpersonal factors, and over $40 \%$ of the variance could be explained by two measures: generosity and negative affect.

Using best subset selection offers insight into the driving forces behind previous findings. For example, while this study replicated previous findings that conservative ideology is linked to believing misinformation (Pennycook \& Rand, 2019, 2021), best subset selection showed that conservative ideology did not explain much about accuracy rates once well-being factors were included in the model. Further, a mediation analysis showed that negative affect and happiness mediated the effects of both social and economic conservatism when predicting the accuracy of both true and false statements. This suggests that the main driving forces linking conservatism and biased information processing may be related to conservatism qua aspects of their well-being rather than conservatism qua ideological beliefs.

The effect sizes of generosity and negative affect were particularly large. This is likely because they are heterogeneous concepts associated with various measures. Generosity has been linked to a general trusting nature (Bekkers, 2007; Chaudhuri \& Gangadharan, 2007), and, as such, it should not be surprising that generosity was associated with a truth bias. Additionally, as previously mentioned, generosity was correlated with well-being measures which also exhibited a bias in truth assessment: negative affect $(r=.55)$ and eudaimonic well-being ( $r=-.34)$. Thus, the large effects of generosity might be caused by its links to multiple measures which all explain different parts of the variance in biased truth assessment. Similarly, the large effects of negative affect might be driven by its relationship to multiple factors which are associated with biased truth assessment. As discussed above, various attentional and information processing biases have been linked to depression (Gotlib \& Joormann, 2010; Keller et al., 2019), low self-esteem (Howell \& Shepperd, 2016; Wiersema et al., 2012), and momentary mood (Holland \& Kensinger, 2010). As such, it was not surprising that well-being was associated with biased truth assessment. Negative affect might be acting as a "catch all" for the various effects of poor well-being as it was highly correlated with depressive symptoms $(r=.64)$, eudaimonic well-being ( $r=-.60)$, momentary anxiety $(r=.67)$, momentary depression $(r=.62)$, and self-esteem $(r=-.21)$. Further, the truth bias is known to increase under cognitive load (Street \& Kingstone, 2017; Street \& Richardson, 2015) and negative affect is associated with reduced working memory (i.e., increased cognitive load) (Curci et al., 2013). As such, the large effect size of negative affect might be due to its links to various aspects of well-being as well as the cognitive associations which are linked to a truth bias.

This work had some limitations. First, it should be noted that the present study used self-report measures. There is evidence that selfreported measures of well-being can be exaggerated (Shrout et al., 2018), so future work could consider how biases in political information processing is related to more objective measures of wellbeing. Second, this work only represents one study, and while the MTurk participant panel is generally representative of the general population in terms of both political ideology (Clifford et al., 2015) and mental health (McCredie \& Morey, 2018), it is always possible in a one-study experiment that the sample was biased. It was recently noted that the MTurk population has a slightly higher tendency toward negative affect and lower social engagement (McCredie \& Morey, 2018). Third, while this study had $90 \%$ power to detect smallmedium effects ( $r=.15$ ), novel, published work is often associated with exaggerated effect sizes, given publication bias (Simonsohn et al., 2014). It is important that these results are replicated in future work.

Political knowledge is associated with more accurate appraisal of news (Vegetti \& Mancosu, 2020), but the present study did not control for this. Future work should consider whether mental well-being and interpersonal factors interact with political knowledge when assessing the veracity of political statements. Somewhat related, since participants did not complete the study in a controlled environment, they could have fact-checked the veracity of each statement during the protocol. Future work might verify whether mental well-being and interpersonal factors were related to a (reduced) willingness to fact- 
check statements during participation. In addition, it should be noted that the above design had individuals offer their initial judgment on the veracity of statements. Just because an individual initially leans toward believing misinformation, does not imply that they would avoid fact-checking the statement at some later date. As such, this work shows that low well-being and high prosociality are linked to a predisposition to believing misinformation. Future work should consider whether individuals overcome this predisposition by factchecking their initial judgments.

This work adds to the nascent literature on whether state affect is linked to vulnerability to misinformation. Martel et al. (2020) found that positive and negative affect (measured with PANAS) were both associated with increased belief in false headlines but not real headlines. Another study experimentally manipulated anxiety and anger; they found no main effect of either emotion on accuracy rates, though they did find that anger and anxiety interacted with the partisan nature of political information (Weeks, 2015). The present work expanded the above by testing several affective and subjective wellbeing factors over various time frames (i.e., in-the-moment emotions, affect over 7 days, and depressive symptoms over 14 days). Various measures of negative affect showed dramatic associations with the tendency to believe both true and false statements. Various measures of positive affect showed small-moderate associations. Future work should attempt to understand why the present work showed strong effects for both false and true information, while the other studies did not. The news headlines that were selected are a potential cause of the divergent results. In this study, all headlines had been deemed worthy to fact check by fact-checking sites; even if they turned out to be true. Martel et al. (2020) used false headlines from fact-checking sites (and their results are similar to the present work) but used true headlines from regular news sites. Perhaps true headlines which factchecking sites deemed worthy of checking are different to the majority of headlines on news sites. Further, Weeks (2015) invented headlines. Perhaps there was some item-effects. Future work should consider this.

This work also adds to the early, and somewhat conflicting, work on prosocial behaviors. Personality traits such agreeableness and conscientiousness have been associated with judging the veracity of political statements (Calvillo et al., 2021), though these were not replicated (Sindermann et al., 2021). Further, Sindermann et al. (2021) found that submissiveness was associated with vulnerability to believe misinformation, but simultaneously found that trusting others protected one from believing misinformation. The present work found that generosity was highly associated with vulnerability to misinformation. Generosity in the Dictator game is likely capturing interpersonal tendencies beyond personality traits, as previous work has shown only small-moderate associations between generosity in the Dictator game and Big Five personality traits, such as agreeableness and conscientiousness (Hilbig et al., 2015). However, as discussed above, generosity is a complex, heterogeneous measure. Future work could delve into the underlying causes for the association between cooperative behavior (both generosity and trust) and vulnerability to the truth bias. Interestingly, despite robust evidence that strength of group alignment is associated with sharing false information (Osmundsen et al., 2021) and believing conspiracy theories (Douglas, 2021; Douglas et al., 2017), there was little evidence that a willingness to pay a cost to help one's ingroup (via the Dictator game) was associated with a general bias (see Table 1) or a partisan bias (see Table D1).

This work corroborates the work of Fasce et al. (2021), which found a positive association between need to belong and belief in misinformation (though their work focused on beliefs outside of the political arena). However, need to belong was one of the smaller effects found in the interpersonal measures. To the author's knowledge, this is the first work to consider whether vulnerability to misinformation is associated with how the outcome of the election might affect friendships. Vulnerability to misinformation was particularly strong if a participant felt that their friendships would be improved if the participant's candidate lost the election. Future work could step beyond the simple correlations presented here and consider whether some individuals are biasing their judgment of news to maintain positive social interactions.

While generosity, high negative affect and low eudaimonic wellbeing were associated with believing most news headlines, low generosity, low negative affect, and high eudaimonic well-being were associated with partisan biases. In fact, for almost every factor measured in this work, if one extreme of the measure was associated with a bias to believe most headlines, the other extreme was associated with a partisan bias. This finding may be relevant to the discussion of motivated reasoning (Persson et al., 2021). There has been some evidence that analytical thinking is associated with a larger partisan bias (Kahan et al., 2017; Nurse \& Grant, 2020), though the findings have not always replicated (Pennycook \& Rand, 2019; Persson et al., 2021). This has led some to suggest that increased analytical ability may help individual bias their beliefs about the world to align with their values. Here we find that (with the exception of the smaller effects of positive affect), higher well-being is associated with increased political bias. While correlation is not causation, this would somewhat fit with the narrative that individuals are motivated to align their ideology with the state of the world, and that this could lead to improved mental health. However, it is impossible to diagnose the causal direction from this data. Either way, when considering the motivated reasoning hypothesis, future work should consider the effects of well-being alongside the effects of analytical thinking.

The present work suggests that poor truth assessment is highly linked to a combination of interpersonal, health, and affective factors. Until now, much of the work has considered the effect of cognitive factors (Martel et al., 2020). Without explicitly considering the cognitive factors which have been shown to relate to accuracy in truth assessment (Bronstein et al., 2019; Pennycook \& Rand, 2019, 2021; Sindermann et al., 2020), over $50 \%$ of the variance could be explained. It is likely that the information processing and attentional biases associated with poor well-being are being (at least partially) captured by the work on cognitive factors. However, future work should consider running best subset selection with interpersonal factors, well-being factors, and such cognitive factors in order to test whether each 
factor explains a unique aspect of individual accuracy rates. Lastly, this work demonstrates that as the effort to create interventions for improving resilience to misinformation increases (van der Linden et al., 2021), it may be important to focus on the individuals prone to the interpersonal and well-being factors which are highly associated with biased judgment of political information.

\section{ACKNOWLEDGMENTS}

I would like to thank Prof. Robert D Rogers and Dr. Rachel Newey for comments and suggestions on early versions of this manuscript.

\section{CONFLICT OF INTEREST}

There is no conflict of interest to report.

\section{DATA AVAILABILITY STATEMENT}

I report all data exclusions, all manipulations, and all measures in the study. Further, I report how I determined the sample size with an a priori power analysis. All data and research materials are available at https://osf.io/3rxv5/?view_only=cfd69f3e9e1a48deb699c2658c2 7 f8af (anonymized for review). This is described in the manuscript. This study's design and analysis were not pre-registered. Paul Rauwolf completed all aspects of this manuscript. The project was funded by Dr. Rauwolf's personal account (no grant affiliations). This work has not been published nor is it being considered by any other journal.

\section{ORCID}

\section{Paul Rauwolf (DD https://orcid.org/0000-0002-4715-8644}

\section{REFERENCES}

Allcott, H., \& Gentzkow, M. (2017). Social media and fake news in the 2016 election. Journal of Economic Perspectives, 31(2), 211-236. https://doi.org/10.1257/jep.31.2.211

Anthony, A., \& Moulding, R. (2019). Breaking the news: Belief in fake news and conspiracist beliefs. Australian Journal of Psychology, 71(2), 154162. https://doi.org/10.1111/ajpy.12233

Bago, B., Rand, D. G., \& Pennycook, G. (2020). Fake news, fast and slow: Deliberation reduces belief in false (but not true) news headlines. Journal of Experimental Psychology: General, 149(8), 1608-1613.

Batailler, C., Brannon, S. M., Teas, P. E., \& Gawronski, B. (2021). A signal detection approach to understanding the identification of fake news. Perspectives on Psychological Science, 17, 78-98.

Bekkers, R. (2007). Measuring altruistic behavior in surveys: The all-ornothing dictator game. Survey Research Methods, 1(3), 139-144. https://doi.org/10.18148/srm/2007.v1i3.54

Bertsimas, D., King, A., \& Mazumder, R. (2016). Best subset selection via a modern optimization lens. The Annals of Statistics, 44(2), 813-852. https://doi.org/10.1214/15-AOS1388

Bishara, A. J., \& Hittner, J. B. (2014). Reducing bias and error in the correlation coefficient due to nonnormality. Educational and Psychological Measurement, 75(5), 785-804. https://doi.org/10.1177/ 0013164414557639

Brashier, N. M., \& Schacter, D. L. (2020). Aging in an era of fake news. Current Directions in Psychological Science, 29(3), 316-323. https://doi. org/10.1177/0963721420915872

Brawley, A. M., \& Pury, C. L. S. (2016). Work experiences on MTurk: Job satisfaction, turnover, and information sharing. Computers in Human Behavior, 54, 531-546. https://doi.org/10.1016/j.chb. 2015.08.031
Bronstein, M. V., Pennycook, G., Bear, A., Rand, D. G., \& Cannon, T. D. (2019). Belief in fake news is associated with delusionality, dogmatism, religious fundamentalism, and reduced analytic thinking. Journal of Applied Research in Memory and Cognition, 8(1), 108-117. https://doi. org/10.1016/j.jarmac.2018.09.005

Byrd, D. R., \& McKinney, K. J. (2012). Individual, interpersonal, and institutional level factors associated with the mental health of college students. Journal of American College Health, 60(3), 185-193. https://doi. org/10.1080/07448481.2011.584334

Calvillo, D. P., Garcia, R. J. B., Bertrand, K., \& Mayers, T. A. (2021). Personality factors and self-reported political news consumption predict susceptibility to political fake news. Personality and Individual Differences, 174, 110666. https://doi.org/10.1016/j.paid.2021.110666

Cameron, J. J., \& Granger, S. (2018). Does self-esteem have an interpersonal imprint beyond self-reports? A meta-analysis of self-esteem and objective interpersonal indicators. Personality and Social Psychology Review, 23(1), 73-102. https://doi.org/10.1177/ 1088868318756532

Caplan, B. (2001). Rational ignorance versus rational irrationality. Kyklos, 54(1), 3-26. https://doi.org/10.1111/1467-6435.00138

Chaudhuri, A., \& Gangadharan, L. (2007). An experimental analysis of trust and trustworthiness. Southern Economic Journal, 73(4), 959-985. https://doi.org/10.1002/j.2325-8012.2007.tb00813.x

Clementson, D. E. (2017). Truth bias and partisan bias in political deception detection. Journal of Language and Social Psychology, 37(4), 407-430. https://doi.org/10.1177/0261927X17744004

Clifford, S., Jewell, R. M., \& Waggoner, P. D. (2015). Are samples drawn from mechanical Turk valid for research on political ideology? Research \& Politics, 2(4), 2053168015622072. https://doi.org/10. $1177 / 2053168015622072$

Crawford, J. R., \& Henry, J. D. (2004). The Positive and Negative Affect Schedule (PANAS): Construct validity, measurement properties and normative data in a large non-clinical sample. British Journal of Clinical Psychology, 43(3), 245-265. https://doi.org/10.1348/ 0144665031752934

Curci, A., Lanciano, T., Soleti, E., \& Rimé, B. (2013). Negative emotional experiences arouse rumination and affect working memory capacity. Emotion, 13(5), 867-880). American Psychological Association. https://doi.org/10.1037/a0032492

De Coninck, D., Frissen, T., Matthijs, K., d'Haenens, L., Lits, G., Champagne-Poirier, O., Carignan, M.-E., David, M. D., PignardCheynel, N., Salerno, S., \& Généreux, M. (2021). Beliefs in conspiracy theories and misinformation about COVID-19: Comparative perspectives on the role of anxiety, depression and exposure to and trust in information sources. Frontiers in Psychology, 12, 646394. https://doi. org/10.3389/fpsyg.2021.646394

Del Vicario, M., Bessi, A., Zollo, F., Petroni, F., Scala, A., Caldarelli, G., Stanley, H. E., \& Quattrociocchi, W. (2016). The spreading of misinformation online. Proceedings of the National Academy of Sciences, 113(3), 554-559. https://doi.org/10.1073/pnas.1517441113

Douglas, K. M. (2021). COVID-19 conspiracy theories. Group Processes \& Intergroup Relations, 24(2), 270-275. https://doi.org/10.1177/ 1368430220982068

Douglas, K. M., Sutton, R. M., \& Cichocka, A. (2017). The psychology of conspiracy theories. Current Directions in Psychological Science, 26(6), 538-542. https://doi.org/10.1177/0963721417718261

Douglas, K. M., Uscinski, J. E., Sutton, R. M., Cichocka, A., Nefes, T., Ang, C. S., \& Deravi, F. (2019). Understanding conspiracy theories. Political Psychology, 40(S1), 3-35. https://doi.org/10.1111/pops. 12568

Ecker, U. K. H., Lewandowsky, S., Cook, J., Schmid, P., Fazio, L. K., Brashier, N., Kendeou, P., Vraga, E. K., \& Amazeen, M. A. (2022). The psychological drivers of misinformation belief and its resistance to correction. Nature Reviews Psychology, 1(1), 13-29. https://doi.org/10. 1038/s44159-021-00006-y 
Egelhofer, J. L., \& Lecheler, S. (2019). Fake news as a two-dimensional phenomenon: A framework and research agenda. Annals of the International Communication Association, 43(2), 97-116. https://doi.org/10. 1080/23808985.2019.1602782

Engel, C. (2011). Dictator games: A meta study. Experimental Economics, 14(4), 583-610. https://doi.org/10.1007/s10683-011-9283-7

Fasce, A., Adrián-Ventura, J., Lewandowsky, S., \& van der Linden, S. (2021). Science through a tribal lens: A group-based account of polarization over scientific facts. Group Processes \& Intergroup Relations, 13684302211050324. https://doi.org/10.1177/ 13684302211050323

Forgas, J. P., \& East, R. (2008). On being happy and gullible: Mood effects on skepticism and the detection of deception. Journal of Experimental Social Psychology, 44(5), 1362-1367. https://doi.org/10.1016/j.jesp. 2008.04.010

Fowler, J. H., \& Kam, C. D. (2007). Beyond the self: Social identity, altruism, and political participation. The Journal of Politics, 69(3), 813-827. https://doi.org/10.1111/j.1468-2508.2007.00577.x

Gallagher, M. W., \& Lopez, S. J. (2009). Positive expectancies and mental health: Identifying the unique contributions of hope and optimism. The Journal of Positive Psychology, 4(6), 548-556. https://doi.org/10.1080/ 17439760903157166

Garrett, K. R., \& Bond, R. M. (2022). Conservatives' susceptibility to political misperceptions. Science Advances, 7(23), eabf1234. https://doi.org/ 10.1126/sciadv.abf1234

Garrett, R. K., Sude, D., \& Riva, P. (2020). Toeing the party lie: Ostracism promotes endorsement of partisan election falsehoods. Political Communication, 37(2), 157-172. https://doi.org/10.1080/10584609. 2019.1666943

Garrett, R. K., Weeks, B. E., \& Neo, R. L. (2016). Driving a wedge between evidence and beliefs: How online ideological news exposure promotes political misperceptions. Journal of Computer-Mediated Communication, 21(5), 331-348. https://doi.org/10.1111/jcc4.12164

Gómez, A., \& Prokopyev, O. A. (2021). A mixed-integer fractional optimization approach to best subset selection. INFORMS Journal on Computing, 33(2), 551-565. https://doi.org/10.1287/ijoc.2020.1031

Gotlib, I. H., \& Joormann, J. (2010). Cognition and depression: Current status and future directions. Annual Review of Clinical Psychology, 6(1), 285-312. https://doi.org/10.1146/annurev.clinpsy.121208.131305

Grinberg, N., Joseph, K., Friedland, L., Swire-Thompson, B., \& Lazer, D. (2019). Fake news on twitter during the 2016 U.S. presidential election. Science, 363(6425), 374-378. https://doi.org/10.1126/science. aau2706

Guess, A. M., \& Lyons, B. A. (2020). Misinformation, disinformation, and online propaganda. In N. Persily \& J. A. Tucker (Eds.), Social media and democracy: The state of the field, prospects for reform (pp. 10-33). Cambridge University Press Cambridge.

Hastie, T., Tibshirani, R., \& Friedman, J. (2001). The elements of statistical learning. Springer Series in Statistics New York (Vol. 1, Issue 10).

Hauser, D. J., \& Schwarz, N. (2016). Attentive Turkers: MTurk participants perform better on online attention checks than do subject pool participants. Behavior Research Methods, 48(1), 400-407. https://doi.org/10. 3758/s13428-015-0578-z

Hilbig, B. E., Thielmann, I., Hepp, J., Klein, S. A., \& Zettler, I. (2015). From personality to altruistic behavior (and back): Evidence from a doubleblind dictator game. Journal of Research in Personality, 55, 46-50. https://doi.org/10.1016/j.jrp.2014.12.004

Hofman, J. M., Watts, D. J., Athey, S., Garip, F., Griffiths, T. L., Kleinberg, J., Margetts, H., Mullainathan, S., Salganik, M. J., Vazire, S., Vespignani, A., \& Yarkoni, T. (2021). Integrating explanation and prediction in computational social science. Nature, 595(7866), 181-188. https://doi.org/10.1038/s41586-021-03659-0

Holland, A. C., \& Kensinger, E. A. (2010). Emotion and autobiographical memory. Physics of Life Reviews, 7(1), 88-131. https://doi.org/10. 1016/j.plrev.2010.01.006
Holm, S. (1979). A simple sequentially Rejective multiple test procedure. Scandinavian Journal of Statistics, 6(2), 65-70. http://www.jstor.org/ stable/4615733

Howell, J. L., \& Shepperd, J. A. (2012). Reducing information avoidance through affirmation. Psychological Science, 23(2), 141-145. https://doi. org/10.1177/0956797611424164

Howell, J. L., \& Shepperd, J. A. (2016). Establishing an information avoidance scale. Psychological Assessment, 28(12), 1695-1708). American Psychological Association. https://doi.org/10.1037/pas0000315

Howell, J. L., \& Shepperd, J. A. (2017). Social exclusion, self-affirmation, and health information avoidance. Journal of Experimental Social Psychology, 68, 21-26. https://doi.org/10.1016/j.jesp.2016.05.005

James, G., Witten, D., Hastie, T., \& Tibshirani, R. (2013). An introduction to statistical learning (Vol. 112). Springer.

Joel, S., Burton, C. M., \& Plaks, J. E. (2014). Conservatives anticipate and experience stronger emotional reactions to negative outcomes. Journal of Personality, 82(1), 32-43. https://doi.org/10.1111/jopy.12031

Kahan, D. M., Peteres, E., Dawson, E. C., \& Slovic, P. (2017). Motivated numeracy and enlightened self-government. Behavioural Public Policy, 1(1), 54-86. https://doi.org/10.1017/bpp.2016.2

Keller, A. S., Leikauf, J. E., Holt-Gosselin, B., Staveland, B. R., \& Williams, L. M. (2019). Paying attention to attention in depression. Translational Psychiatry, 9(1), 279. https://doi.org/10.1038/s41398019-0616-1

Keyes, C. L. M. (2006). Subjective well-being in mental health and human development research worldwide: An introduction. Social Indicators Research, 77(1), 1-10. https://doi.org/10.1007/s11205-005-5550-3

Keyes, C. L. M., Shmotkin, D., \& Ryff, C. D. (2002). Optimizing well-being: The empirical encounter of two traditions. Journal of Personality and social Psychology, 82(6), 1007-1022). American Psychological Association. https://doi.org/10.1037/0022-3514.82.6.1007

Lazer, D. M. J., Baum, M. A., Benkler, Y., Berinsky, A. J., Greenhill, K. M., Menczer, F., Metzger, M. J., Nyhan, B., Pennycook, G., Rothschild, D., Schudson, M., Sloman, S. A., Sunstein, C. R., Thorson, E. A., Watts, D. J., \& Zittrain, J. L. (2018). The science of fake news. Science, 359(6380), 1094-1096. https://doi.org/10.1126/science.aao2998

Levine, T. R., Park, H. S., \& McCornack, S. A. (1999). Accuracy in detecting truths and lies: Documenting the "veracity effect.". Communication Monographs, 66(2), 125-144. https://doi.org/10.1080/036377599093 76468

Lumley, T., Diehr, P., Emerson, S., \& Chen, L. (2002). The importance of the normality assumption in large public health data sets. Annual Review of Public Health, 23(1), 151-169. https://doi.org/10.1146/ annurev.publhealth.23.100901.140546

Martel, C., Pennycook, G., \& Rand, D. G. (2020). Reliance on emotion promotes belief in fake news. Cognitive Research: Principles and Implications, 5(1), 47. https://doi.org/10.1186/s41235-020-00252-3

Martela, F., \& Sheldon, K. M. (2019). Clarifying the concept of well-being: Psychological need satisfaction as the common Core connecting eudaimonic and subjective well-being. Review of General Psychology, 23(4), 458-474. https://doi.org/10.1177/1089268019880886

Mazumder, R., Friedman, J. H., \& Hastie, T. (2011). SparseNet: Coordinate descent with nonconvex penalties. Journal of the American Statistical Association, 106(495), 1125-1138. https://doi.org/10.1198/jasa.2011. tm09738

Mccornack, S. A., \& Parks, M. R. (1986). Deception detection and relationship development: The other side of trust. Annals of the International Communication Association, 9(1), 377-389. https://doi.org/10.1080/ 23808985.1986.11678616

McCredie, M. N., \& Morey, L. C. (2018). Who are the Turkers? A characterization of MTurk workers using the personality assessment inventory. Assessment, 26(5), 759-766. https://doi.org/10.1177/1073191118760709

Memon, M. A., Jun, H. C., Ting, H., \& Francis, C. W. (2018). Mediation analysis issues and recommendations. Journal of Applied Structural Equation Modeling, 2(1), i-ix. 
Mosleh, M., Martel, C., Eckles, D., \& Rand, D. G. (2021). Shared partisanship dramatically increases social tie formation in a Twitter field experiment. Proceedings of the National Academy of Sciences, 118(7), e2022761118. https://doi.org/10.1073/pnas.2022761118

Nichols, A. L., \& Webster, G. D. (2013). The single-item need to belong scale. Personality and Individual Differences, 55(2), 189-192. https:// doi.org/10.1016/j.paid.2013.02.018

Nurse, M. S., \& Grant, W. J. (2020). I'll see it when I believe it: Motivated numeracy in perceptions of climate change risk. Environmental Communication, 14(2), 184-201. https://doi.org/10.1080/17524032.2019. 1618364

Osmundsen, M., Bor, A., Vahlstrup, P. B., Bechmann, A., \& Petersen, M. B. (2021). Partisan polarization is the primary psychological motivation behind political fake news sharing on Twitter. American Political Science Review, 115(3), 999-1015. https://doi.org/10.1017/ S0003055421000290

Pennycook, G., \& Rand, D. G. (2019). Lazy, not biased: Susceptibility to partisan fake news is better explained by lack of reasoning than by motivated reasoning. Cognition, 188, 39-50. https://doi.org/10.1016/ j.cognition.2018.06.011

Pennycook, G., \& Rand, D. G. (2021). The psychology of fake news. Trends in Cognitive Sciences, 25(5), 388-402. https://doi.org/10.1016/j.tics. 2021.02.007

Pereira, A., Harris, E., \& Van Bavel, J. J. (2021). Identity concerns drive belief: The impact of partisan identity on the belief and dissemination of true and false news. Group Processes \& Intergroup Relations, 136843022110300. https://doi.org/10.1177/13684302211030004

Persson, E., Andersson, D., Koppel, L., Västfjäll, D., \& Tinghög, G. (2021). A preregistered replication of motivated numeracy. Cognition, 214, 104768. https://doi.org/10.1016/j.cognition.2021.104768

Rand, D. G., Pfeiffer, T., Dreber, A., Sheketoff, R. W., Wernerfelt, N. C., \& Benkler, Y. (2009). Dynamic remodeling of in-group bias during the 2008 presidential election. Proceedings of the National Academy of Sciences, 106(15), 6187-6191. https://doi.org/10.1073/pnas.0811552106

Rathje, S., Van Bavel, J. J., \& van der Linden, S. (2021). Out-group animosity drives engagement on social media. Proceedings of the National Academy of Sciences, 118(26), e2024292118. https://doi.org/10. 1073/pnas.2024292118

Rauwolf, P., Mitchell, D., \& Bryson, J. J. (2015). Value homophily benefits cooperation but motivates employing incorrect social information. Journal of Theoretical Biology, 367, 246-261. https://doi.org/10.1016/ j.jtbi.2014.11.023

Reilly, T. J., MacGillivray, S. A., Reid, I. C., \& Cameron, I. M. (2015). Psychometric properties of the 16-item quick inventory of depressive symptomatology: A systematic review and meta-analysis. Journal of Psychiatric Research, 60, 132-140. https://doi.org/10.1016/j. jpsychires.2014.09.008

Robins, R. W., Hendin, H. M., \& Trzesniewski, K. H. (2001). Measuring Global Self-Esteem: Construct validation of a single-item measure and the Rosenberg Self-Esteem Scale. Personality and Social Psychology Bulletin, 27(2), 151-161. https://doi.org/10.1177/0146167201272002

Rush, A. J., Trivedi, M. H., Ibrahim, H. M., Carmody, T. J., Arnow, B., Klein, D. N., Markowitz, J. C., Ninan, P. T., Kornstein, S., Manber, R., Thase, M. E., Kocsis, J. H., \& Keller, M. B. (2003). The 16-item quick inventory of depressive symptomatology (QIDS), clinician rating (QIDS-C), and self-report (QIDS-SR): A psychometric evaluation in patients with chronic major depression. Biological Psychiatry, 54(5), 573-583. https://doi.org/10.1016/S0006-3223(02)01866-8

Ryan, R. M., \& Deci, E. L. (2001). On happiness and human potentials: A review of research on hedonic and Eudaimonic well-being. Annual Review of Psychology, 52(1), 141-166. https://doi.org/10.1146/ annurev.psych.52.1.141

Ryff, C. D. (2017). Eudaimonic well-being, inequality, and health: Recent findings and future directions. International Review of Economics, 64(2), 159-178. https://doi.org/10.1007/s12232-017-0277-4
Ryff, C. D., Boylan, J. M., \& Kirsch, J. A. (2021). Eudaimonic and hedonic well-being. In M. T. Lee, L. D. Kubzansky, \& T. J. VanderWeele (Eds.), Measuring well-beinginterdisciplinary perspectives from the social sciences and the humanities measuring well-being: Interdisciplinary perspectives from the social sciences and the humanities. Oxford University Press.

Ryff, C. D., \& Keyes, C. L. M. (1995). The structure of psychological wellbeing revisited. Journal of Personality and Social Psychology, 69(4), 719727). American Psychological Association. https://doi.org/10.1037/ 0022-3514.69.4.719

Ryff, C. D., \& Singer, B. H. (2008). Know thyself and become what you are: A eudaimonic approach to psychological well-being. Journal of Happiness Studies, 9(1), 13-39.

Scheufele, D. A., \& Krause, N. M. (2019). Science audiences, misinformation, and fake news. Proceedings of the National Academy of Sciences, 116(16), 7662-7669. https://doi.org/10.1073/pnas.1805871115

Schmukle, S. C., Egloff, B., \& Burns, L. R. (2002). The relationship between positive and negative affect in the positive and negative affect schedule. Journal of Research in Personality, 36(5), 463-475. https://doi.org/ 10.1016/S0092-6566(02)00007-7

Shrout, P. E., Stadler, G., Lane, S. P., McClure, M. J., Jackson, G. L., Clavél, F. D., lida, M., Gleason, M. E. J., Xu, J. H., \& Bolger, N. (2018). Initial elevation bias in subjective reports. Proceedings of the National Academy of Sciences, 115(1), E15-E23. https://doi.org/10.1073/pnas. 1712277115

Simonsohn, U., Nelson, L. D., \& Simmons, J. P. (2014). P-curve and effect size: Correcting for publication bias using only significant results. Perspectives on Psychological Science, 9(6), 666-681. https://doi.org/10. 1177/1745691614553988

Sindermann, C., Cooper, A., \& Montag, C. (2020). A short review on susceptibility to falling for fake political news. Current Opinion in Psychology, 36, 44-48. https://doi.org/10.1016/j.copsyc.2020.03.014

Sindermann, C., Schmitt, H. S., Rozgonjuk, D., Elhai, J. D., \& Montag, C. (2021). The evaluation of fake and true news: On the role of intelligence, personality, interpersonal trust, ideological attitudes, and news consumption. Heliyon, 7(3), e06503. https://doi.org/10.1016/j.heliyon. 2021.e06503

Sternisko, A., Cichocka, A., \& Van Bavel, J. J. (2020). The dark side of social movements: Social identity, non-conformity, and the lure of conspiracy theories. Current Opinion in Psychology, 35, 1-6. https://doi.org/ 10.1016/j.copsyc.2020.02.007

Street, C. N. H., \& Kingstone, A. (2017). Aligning Spinoza with Descartes: An informed Cartesian account of the truth bias. British Journal of Psychology, 108(3), 453-466. https://doi.org/10.1111/bjop.12210

Street, C. N. H., \& Richardson, D. C. (2015). Descartes versus Spinoza: Truth, uncertainty, and bias. Social Cognition, 33(3), 227-239. https:// doi.org/10.1521/soco.2015.33.2.2

Tandoc, E. C., Lim, Z. W., \& Ling, R. (2018). Defining “Fake News.”. Digital Journalism, 6(2), 137-153. https://doi.org/10.1080/21670811.2017. 1360143

Tappin, B. M., Pennycook, G., \& Rand, D. G. (2020). Bayesian or biased? Analytic thinking and political belief updating. Cognition, 204, 104375. https://doi.org/10.1016/j.cognition.2020.104375

Tov, W. (2018). Well-being concepts and components. In Handbook of well-being. (pp. 43-57). Noba Scholar.

Van Bavel, J. J., Harris, E. A., Pärnamets, P., Rathje, S., Doell, K. C., \& Tucker, J. A. (2021). Political psychology in the digital (mis)information age: A model of news belief and sharing. Social Issues and Policy Review, 15(1), 84-113. https://doi.org/10.1111/sipr.12077

Van Bavel, J. J., \& Pereira, A. (2018). The partisan brain: An identity-based model of political belief. Trends in Cognitive Sciences, 22(3), 213-224. https://doi.org/10.1016/j.tics.2018.01.004

van der Linden, S., Roozenbeek, J., Maertens, R., Basol, M., Kácha, O., Rathje, S., \& Traberg, C. S. (2021). How can psychological science help counter the spread of fake news? The Spanish Journal of Psychology, 24, e25. https://doi.org/10.1017/SJP.2021.23 
van Dierendonck, D. (2004). The construct validity of Ryff's scales of psychological well-being and its extension with spiritual well-being. Personality and Individual Differences, 36(3), 629-643. https://doi.org/10. 1016/S0191-8869(03)00122-3

Vegetti, F., \& Mancosu, M. (2020). The impact of political sophistication and motivated reasoning on misinformation. Political Communication, 37(5), 678-695. https://doi.org/10.1080/10584609.2020. 1744778

Vera-Villarroel, P., Urzúa, A., Jaime, D., Contreras, D., Zych, I., CelisAtenas, K., Silva, J. R., \& Lillo, S. (2017). Positive and negative affect schedule (PANAS): Psychometric properties and discriminative capacity in several Chilean samples. Evaluation \& the Health Professions, 42(4), 473-497. https://doi.org/10.1177/01632787177 45344

Watson, D., Clark, L. A., \& Tellegen, A. (1988). Development and validation of brief measures of positive and negative affect: The PANAS scales. Journal of Personality and Social Psychology, 54(6), 1063-1070). American Psychological Association. https://doi.org/10.1037/0022-3514. 54.6.1063

Weeks, B. E. (2015). Emotions, partisanship, and misperceptions: How anger and anxiety moderate the effect of partisan bias on susceptibility to political misinformation. Journal of Communication, 65(4), 699719. https://doi.org/10.1111/jcom.12164

Weeks, B. E., \& Gil de Zúñiga, H. (2021). What's next? Six observations for the future of political misinformation research. American Behavioral Scientist, 65(2), 277-289. https://doi.org/10.1177/0002764219878236

Wen, Z., \& Fan, X. (2015). Monotonicity of effect sizes: Questioning kappa-squared as mediation effect size measure. Psychological Methods, 20(2), 193-203. https://doi.org/10.1037/met0000029

Whitt, S., Yanus, A. B., McDonald, B., Graeber, J., Setzler, M., Ballingrud, G., \& Kifer, M. (2021). Tribalism in America: Behavioral experiments on affective polarization in the trump era. Journal of Experimental Political Science, 8(3), 247-259. https://doi.org/10.1017/ XPS.2020.29
Wiersema, D. V., van Harreveld, F., \& van der Pligt, J. (2012). Shut your eyes and think of something Else: Self-esteem and avoidance when dealing with counter-attitudinal information. Social Cognition, 30(3), 323-334. https://doi.org/10.1521/soco.2012.30.3.323

Williams, K. D., \& Nida, S. A. (2011). Ostracism: Consequences and coping. Current Directions in Psychological Science, 20(2), 71-75. https://doi. org/10.1177/0963721411402480

Wilson, H., Rauwolf, P., \& Bryson, J. J. (2021). Evolutionary psychology and artificial intelligence: The impact of artificial intelligence on human behaviour. In T. K. Shackelford (Ed.), The SAGE handbook of evolutionary psychology: Applications of evolutionary psychology. (pp. 333-351). SAGE Publications Ltd..

Wojcik, S. P., Hovasapian, A., Graham, J., Motyl, M., \& Ditto, P. H. (2015). Conservatives report, but liberals display, greater happiness. Science, 347(6227), 1243-1246. https://doi.org/10.1126/science.1260817

Wright, D. B., London, K., \& Field, A. P. (2011). Using bootstrap estimation and the plug-in principle for clinical psychology data. Journal of Experimental Psychopathology, 2(2), 252-270. https://doi.org/10.5127/jep.013611

Yarkoni, T., \& Westfall, J. (2017). Choosing prediction over explanation in psychology: Lessons from machine learning. Perspectives on Psychological Science, 12(6), 1100-1122. https://doi.org/10.1177/1745691617693393

\section{SUPPORTING INFORMATION}

Additional supporting information may be found in the online version of the article at the publisher's website.

How to cite this article: Rauwolf, P. (2022). Interpersonal factors and mental well-being are associated with accuracy in judging the veracity of political news. Applied Cognitive Psychology, 1-21. https://doi.org/10.1002/acp.3946 